\title{
Reassessing Alkyne Coupling Reactions While Studying the Electronic Properties of Diverse Pyrene Linkages at Surfaces
}

\author{
James Lawrence ${ }^{1,2}$, Mohammed S. G. Mohammed ${ }^{1,2}$, Dulce Rey, ${ }^{3}$ Fernando Aguilar-Galindo, ${ }^{1}$ Alejandro \\ Berdonces-Layunta ${ }^{1,2}$, Diego Peña ${ }^{3}$, Dimas G. de Oteyza ${ }^{1,2,4}$ \\ ${ }^{l}$ Donostia International Physics Center, 20018 San Sebastián, Spain \\ ${ }^{2}$ Centro de Física de Materiales, 20018 San Sebastián, Spain \\ ${ }^{3}$ Centro Singular de Investigación en Química Biolóxica e Materiais Moleculares (CiQUS) and \\ Departamento de Química Orgánica, Universidade de Santiago de Compostela, 15782 Santiago de Compostela, Spain \\ ${ }^{4}$ Ikerbasque, Basque Foundation for Science, 48011 Bilbao, Spain
}

\section{SUPPORTING INFORMATION}

\section{Self-assembly and tip-induced debromination of 1-bromo-2-ethynylpyrene (M1)}

We have designated the two types of self-assembled dimers observed with precursor M1 on Au(111) as 'cis' and 'trans' according to their shape. The structural models and abundances for both are shown in main paper fig. 1(d). The model for the more common 'cis' type dimer is also supported by high-resolution BR-STM imaging performed with a CO tip (Fig. S1(a) and (b)) - similar imaging could not be used for the 'trans' dimers nor the isolated molecules due to their susceptibility to interactions with the STM tip. Both 'cis' and 'trans' dimers are held together by intermolecular interactions that are related to halogen bonding, or the equivalent alkyne-alkyne interaction that has been seen in other works. ${ }^{1,2}$ Both halogen and alkyne functional groups have been previously shown to possess a so-called 'sigma hole' in their electrostatic potential, allowing electrostatic interactions that can govern molecular self-assembly. ${ }^{3,4}$ The more common 'cis' dimer involves a type I halogen bond between CBr groups as well as an alkyne-alkyne interaction. The 'trans' dimer, on the other hand, has two mixed halogenalkyne interactions. Theoretical calculations of the two observed structures in a free-standing configuration reveal that both, cis and trans, share a similar intermolecular binding energy, with a difference of only $13.6 \mathrm{meV}$ that is within the error margin of the calculations. This explains that both are observed, and the difference in relative abundance may relate to different interactions with the substrate. The cis structure is neither fully planar nor fully symmetric, as evidenced in the calculations and observed experimentally in the BR-image of Fig. S1. It is presumably that asymmetry and non-planarity which allows for an attractive halogen bonding interaction for the cis dimer. However, from our experiments the following alternative scenario cannot be fully discarded either. Although the distances between dimers don't allow a Au adatom to be intercalated coordinating the respective $\mathrm{Br}$ atoms, a similar coordination may be facilitated by a surface atom that is only slightly pulled out of the surface.

The molecules are also found to be particularly susceptible to damage via bias voltage pulses. Fig. S2 shows STM images before and after a series of small $(+2 \mathrm{~V})$ voltage pulses were applied with the tip in close proximity to the molecules. We speculate that the molecules most probably undergo tip-induced debromination, ${ }^{5,6}$ leaving behind radicals bound to the $\mathrm{Au}(111)$ surface. The debrominated molecule takes on a distinctive asymmetric shape when scanned at negative bias voltages, with a corresponding peak in the dI/dV spectra (Fig. S2(c)). The spatial 
distribution of this state as imaged by constant height dI/dV imaging (Fig. S2(d)) bears a resemblance to the highest occupied states of the other pyrene species that are also found in this study. The ease with which the molecules were altered by recording $\mathrm{dI} / \mathrm{dV}$ spectra and bias voltage pulses prevented any measurements of the energetic position of the unoccupied electronic states of the intact molecule.

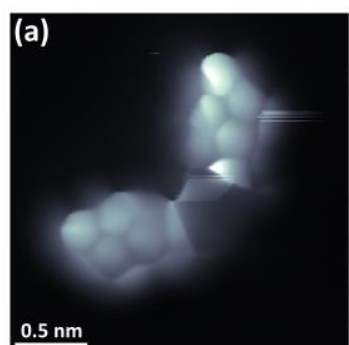

(b)
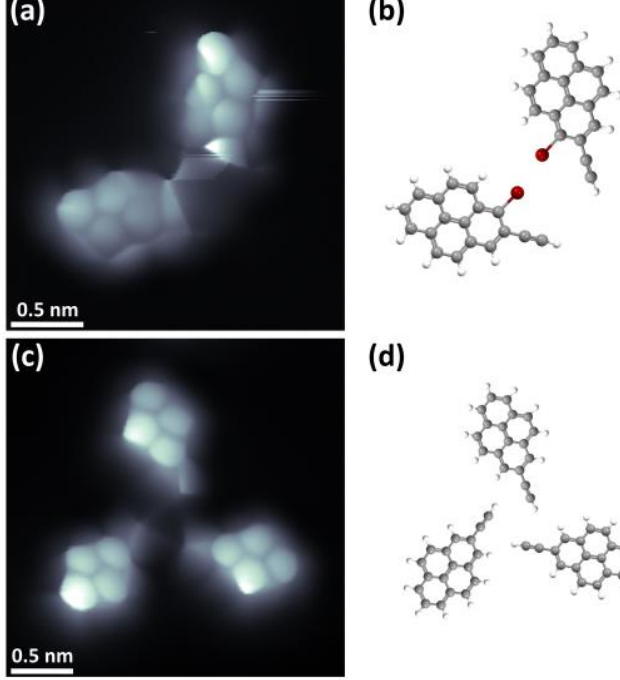

(d)

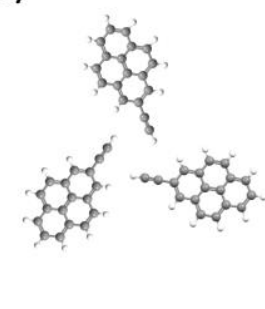

Figure S1. (a) and (b) BR-STM (CO tip, constant height, $5 \mathrm{mV}$ ) and a scaled molecular model (not a calculated structure) of the cis-type self-assembled dimers of the intact precursor molecule M1. (c) and (d) BR-STM (CO tip, constant height, $5 \mathrm{mV}$ ) and molecular model of the self-assembled trimers of the molecule after the loss of bromine from its structure $(\mathbf{M 2})$ at $100^{\circ} \mathrm{C}$. It is assumed that the resulting radical has been passivated, as nonpassivated radicals can form metal-organic structures, as seen in Fig. S5. 

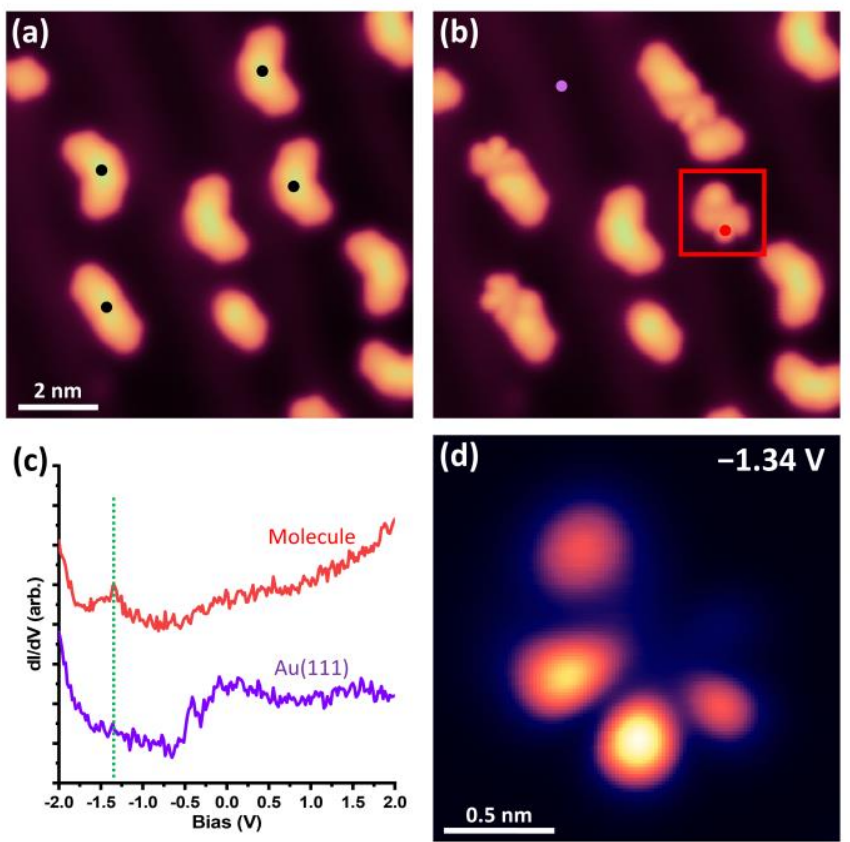

Figure S2. (a) and (b) STM images $(-1.5 \mathrm{~V}, 200 \mathrm{pA})$ of intact precursor molecules (M1) before and after $+2 \mathrm{~V}$ pulses and dI/dV spectra at the positions indicated with black spots. (c) dI/dV spectra recorded at the positions indicated with coloured dots in (b). A peak at approximately $-1.34 \mathrm{~V}$ is marked with a dashed green line. (d) Constant height $\mathrm{dI} / \mathrm{dV}$ image at $-1.34 \mathrm{~V}$ of the molecule indicated with the red box in (b). This is most probably the highest occupied state of the debrominated molecule. Recording another spectrum did not change the molecule any further.
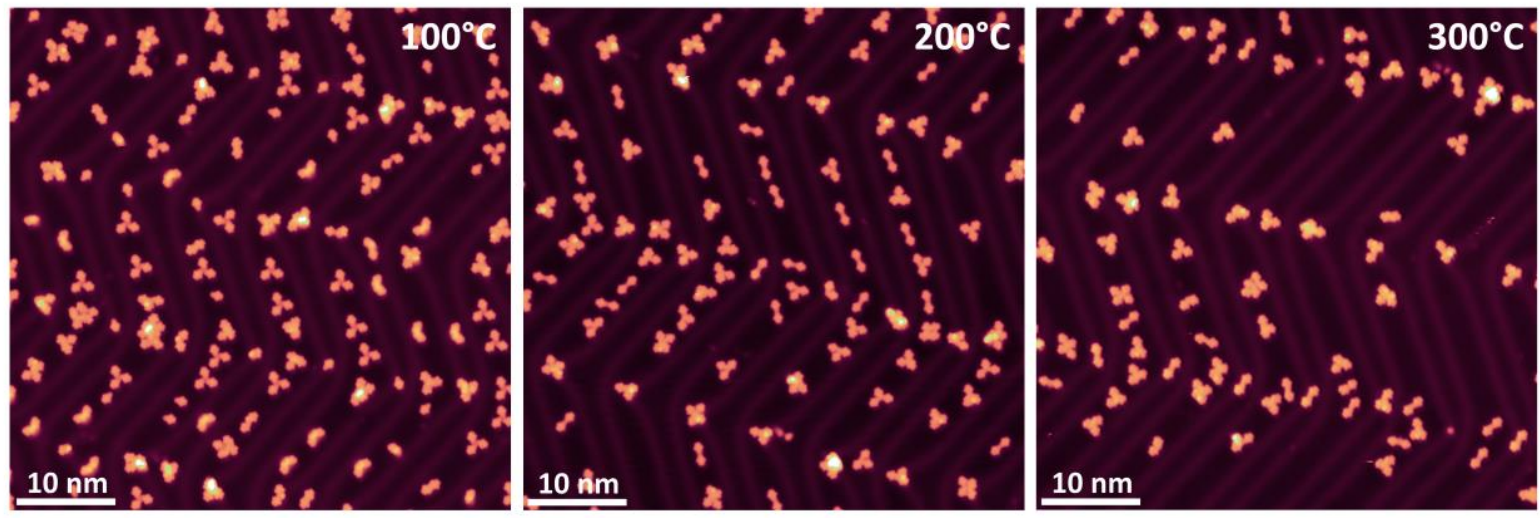

Figure S3. Large-scale STM images after annealing 1-bromo-2-ethynylpyrene $\mathbf{M 1}$ to $100^{\circ} \mathrm{C}, 200^{\circ} \mathrm{C}$ and $300^{\circ} \mathrm{C}$.

(a)

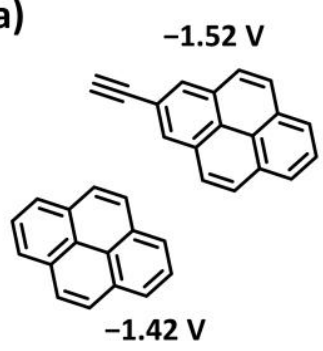

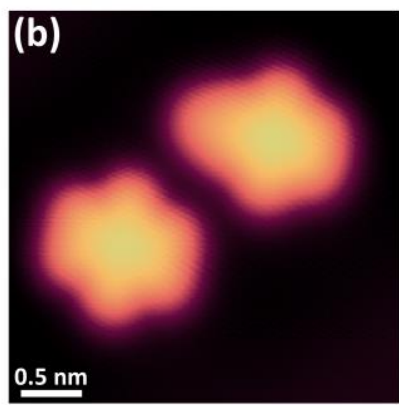

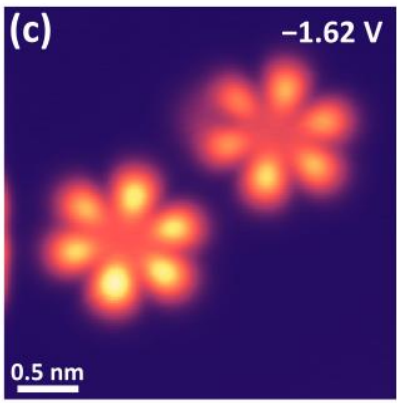


Figure S4. (a) Chemical structures of pyrene and 2-ethynyl-pyrene, with the onset of their highest occupied states as measured by STS. (b) STM image $(-1.5 \mathrm{~V}, 50 \mathrm{pA})$ of the two molecules that were found adjacent to one other. (c) Constant height $\mathrm{dI} / \mathrm{dV}$ image of the two molecules, recorded at a voltage that is slightly more negative than both of their HOMO resonances so that the spatial distribution of this state could be easily imaged for both molecules. A small amount of extra dI/dV signal (relative to pyrene) can be observed at the position of the alkyne group.

\section{Monomers}

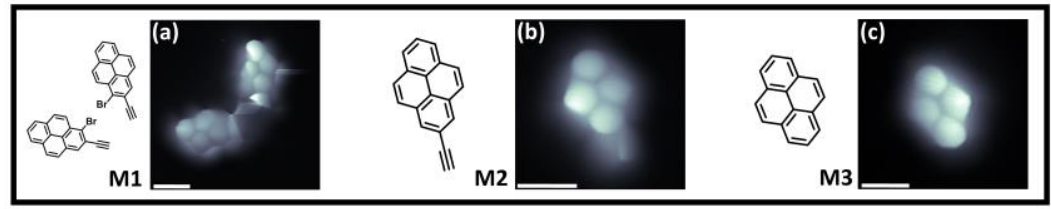

Dimers

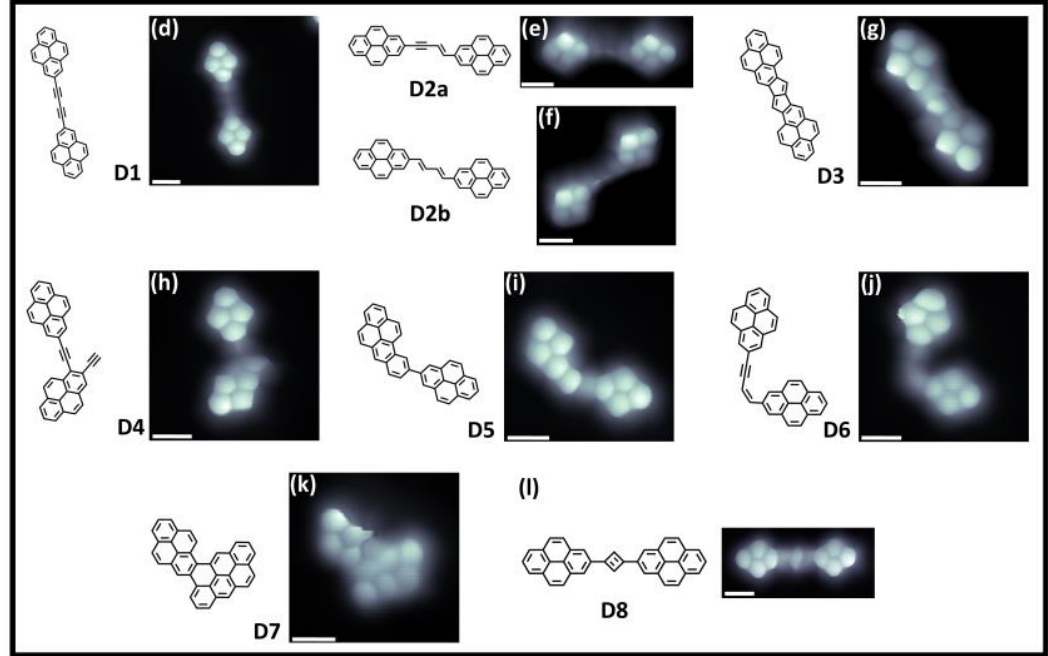

Trimers

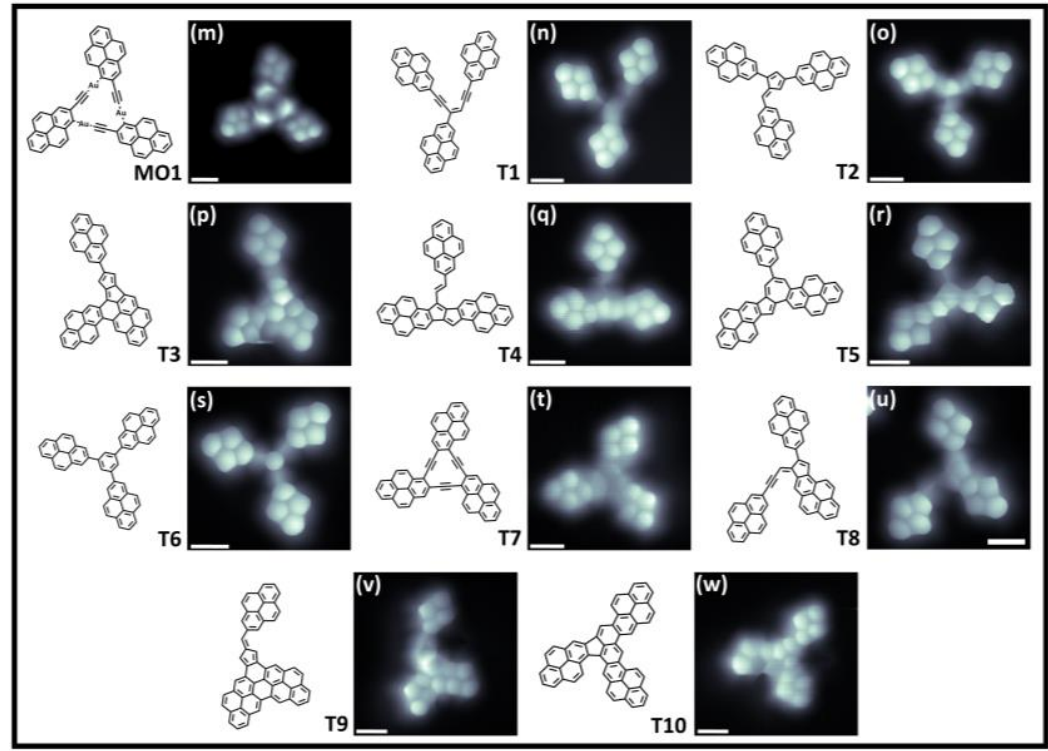

Tetramers

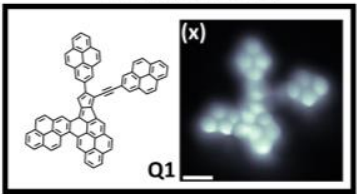


Figure S5. Chemical structures and BR-STM images (constant height, CO tip, 2-5 mV) of all of the identified molecules seen throughout this study. All scale bars are $500 \mathrm{pm}$.
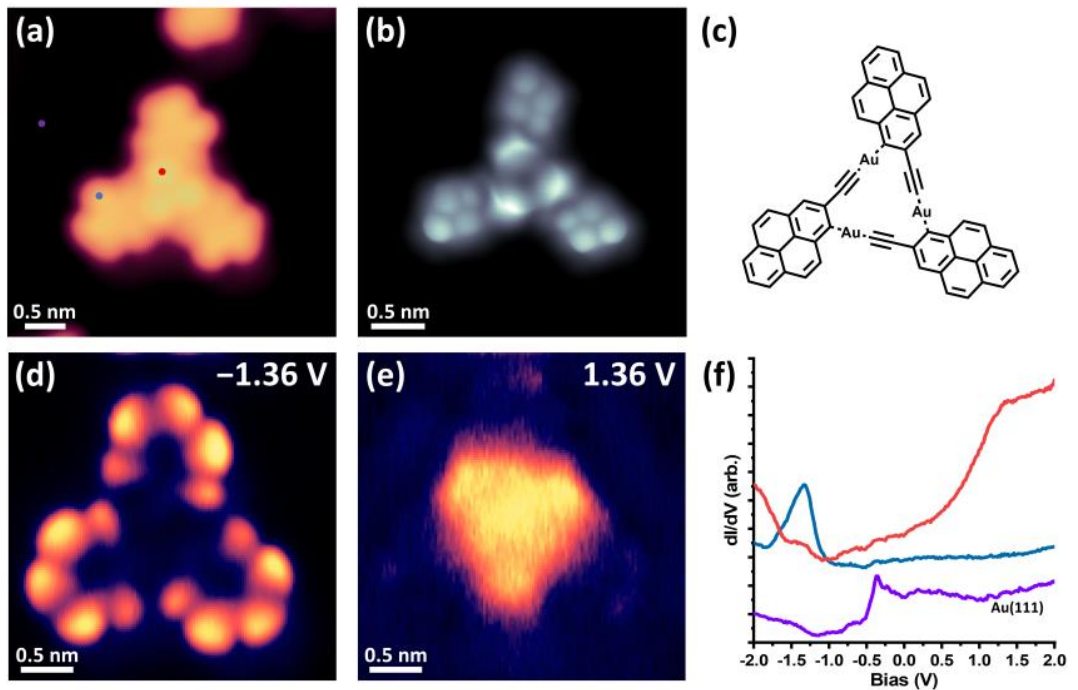

Figure S6. (a) Typical STM image of a metal-organic trimer (MO1) (-1.36 V, 50 pA). (b) BR-STM image of the same trimer (CO tip, constant height, $5 \mathrm{mV}$ ). The bright features correspond well to the position of the metalorganic coordinative bonds. The part of the molecule bound to the metal is noticeably darker with less distortion, perhaps indicating that the molecules are tilted towards the surface. (c) Chemical structure of the metal-organic trimer. (d) and (e) Constant current dI/dV images of the same trimer at the highest occupied and lowest unoccupied states taken from the $\mathrm{dI} / \mathrm{dV}$ point spectra that are shown in (f) and recorded at the positions indicated in (a).

\begin{tabular}{|c|c|c|c|c|c|}
\hline \multicolumn{6}{|c|}{$200^{\circ} \mathrm{C}$ Anneal } \\
\hline Structure & \% Molecules & \% Pyrenes & Structure & $\%$ Molecules & \% Pyrenes \\
\hline D1 & 36.3 & 26.5 & & 1.8 & 2.0 \\
\hline T3 & 11.7 & 12.9 & D3 & 2.1 & 1.6 \\
\hline $\mathrm{T} 1$ & 11.4 & 12.5 & D6 & 1.8 & 1.3 \\
\hline & 7.1 & 10.4 & & 1.8 & 1.3 \\
\hline TS & 3.6 & 3.9 & $\mathrm{~T} 2$ & 1.1 & 1.2 \\
\hline Т8 & 2.8 & 3.1 & & 0.4 & 0.4 \\
\hline T4 & 2.8 & 3.1 & OTHER & 15.3 & 19.9 \\
\hline
\end{tabular}




\begin{tabular}{|c|c|c|c|c|c|}
\hline \multicolumn{6}{|c|}{$300^{\circ} \mathrm{C}$ Anneal } \\
\hline Structure & $\%$ Molecules & \% Pyrenes & Structure & $\%$ Molecules & \% Pyrenes \\
\hline D2 88 & 23.7 & 16.5 & T9 & 2.1 & 2.2 \\
\hline${ }^{\mathrm{T}}$ & 15.5 & 16.2 & & 1.5 & 1.6 \\
\hline $\mathrm{T} 4$ & 7.3 & 7.6 & & 1.5 & 1.6 \\
\hline T5 & 6.1 & 6.3 & D1 & 2.1 & 1.5 \\
\hline & 4.0 & 4.1 & D3 & 0.9 & 0.6 \\
\hline a1 & 2.7 & 3.8 & T1 & 0.3 & 0.3 \\
\hline D5 & 4.3 & 3.0 & 18 & 0.3 & 0.3 \\
\hline D6 88 & 3.3 & 2.3 & OTHER & 24.3 & 32.1 \\
\hline
\end{tabular}

Table S1 and S2. The statistics for the abundance of the various observed products at both $200^{\circ} \mathrm{C}$ and $300^{\circ} \mathrm{C}$ annealing temperatures. Any that only appeared once/were irregular structures (e.g. nanographenes from more extensive dehydrogenation reactions) are included in 'other'. Table S1: 281 molecules (769 pyrenes) counted. Table S2: 329 molecules (947 pyrenes) counted.

\section{Reaction mechanism proposals:}

Presented in the following are suggestions for reaction mechanisms that yield some of the more common products. It is important to note that there may be multiple pathways that yield the same product. For example, intermediates that possess radicals may be passivated before undergoing further radical mechanisms, but still eventually react to form the same or similar products $e . g$. though dehydrogenation reactions.

In our case, as the various reaction intermediates are often observed in STM without any noticeable features that would correspond to surface-stabilized radicals (e.g. pointing down into the $\mathrm{Au}(111)$ surface with a darker appearance in BR-STM or the obvious presence of stabilizing metal adatoms), neither of the two routes can be ruled out. The almost complete disappearance of the cis-enediyne trimer $\mathbf{T} 1$ after the $300^{\circ} \mathrm{C}$ annealing fits well with this interpretation, as there was no indication of it possessing a radical when studied via BR-STM. Regardless of which may be the dominant pathway, it is worth remarking the unusually favored fulvene formation (T2) in the enediyne cyclization, which subsequently evolves to form a pentalene unit that, as is shown in the main text, has an important influence on the product's electronic properties. 
It is worth mentioning here that all of the trimer products along the main reaction pathway in Scheme 2 are also found when annealing M2. Starting from M2, however, only dimers D2a and D2b form, with no examples of dimer D1 observed. This implies that trimer T1 and all of the following products can also be formed by the dimer D2a, further demonstrating that multiple reaction mechanisms may yield these main products. As expected, no Sonogashira-related products were observed when annealing monomer M2.
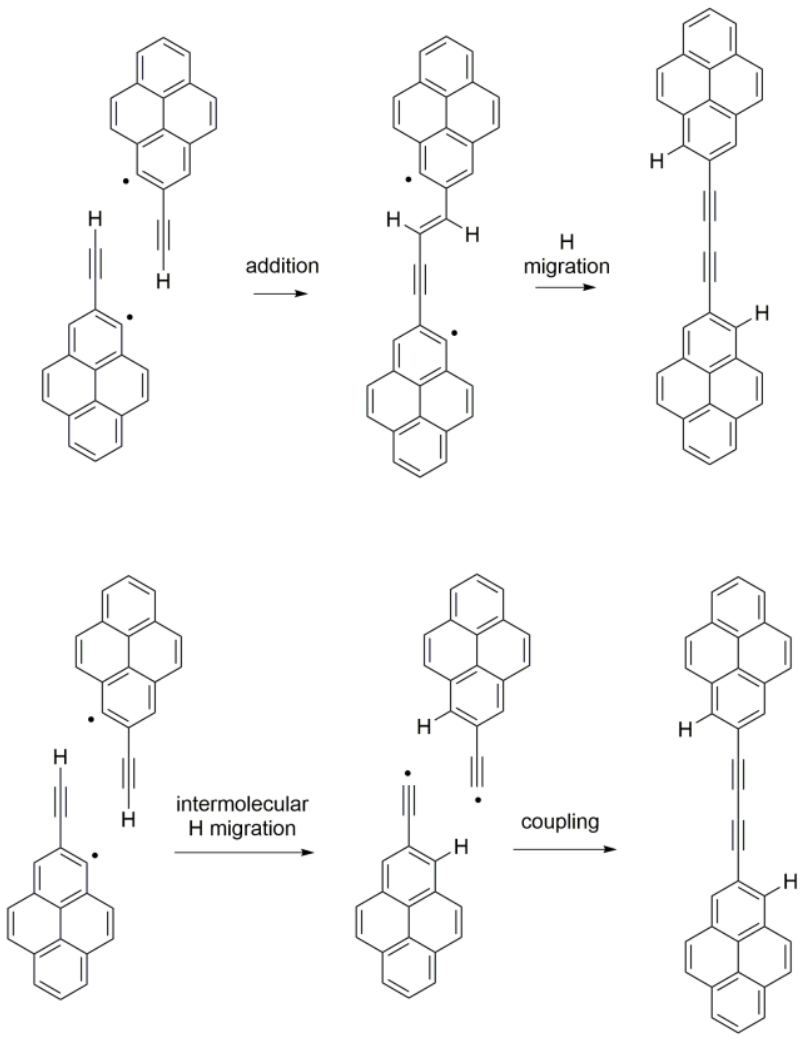

Figure S7. Possible routes to the formation of the Glaser coupled dimer, beginning with the brominated precursor. Hydrogen migration may take place before or after the initial formation of the dimer.

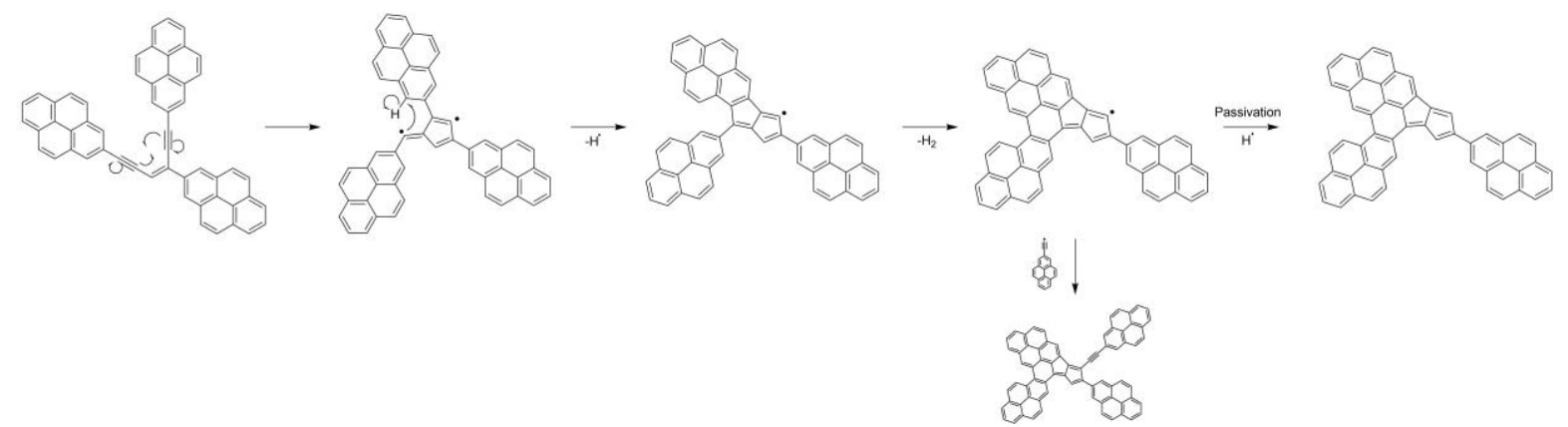

Figure S8. A possible reaction mechanism to form the fused trimer T3 from the cis-enediyne trimer T1. Also included is a suggestion for the origin of the tetramer Q1. 


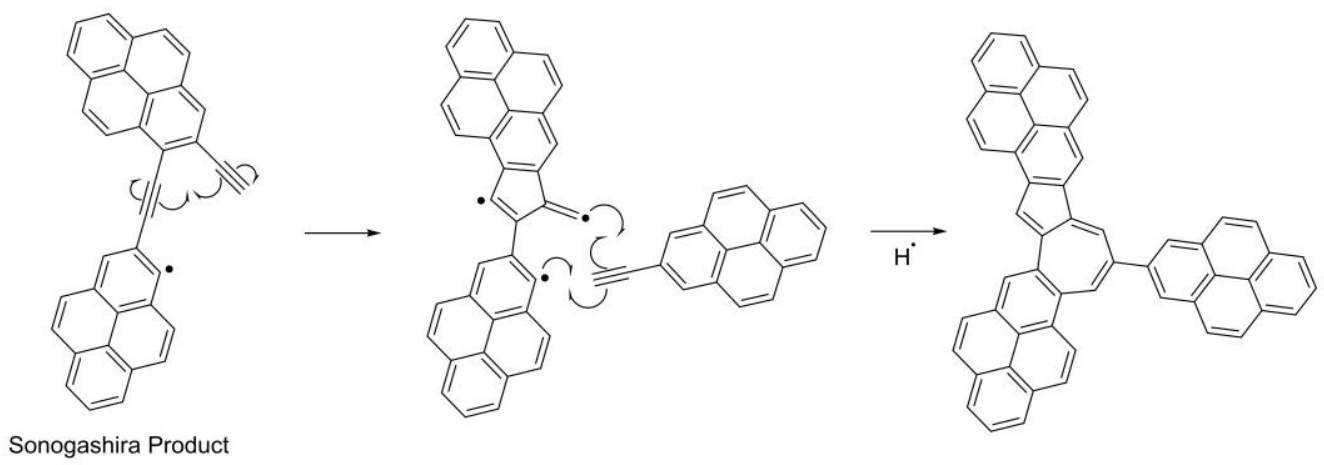

Figure S9. A possible mechanism for the formation of the trimer (T5) containing the 7-membered ring, starting from a simple Sonogashira product.
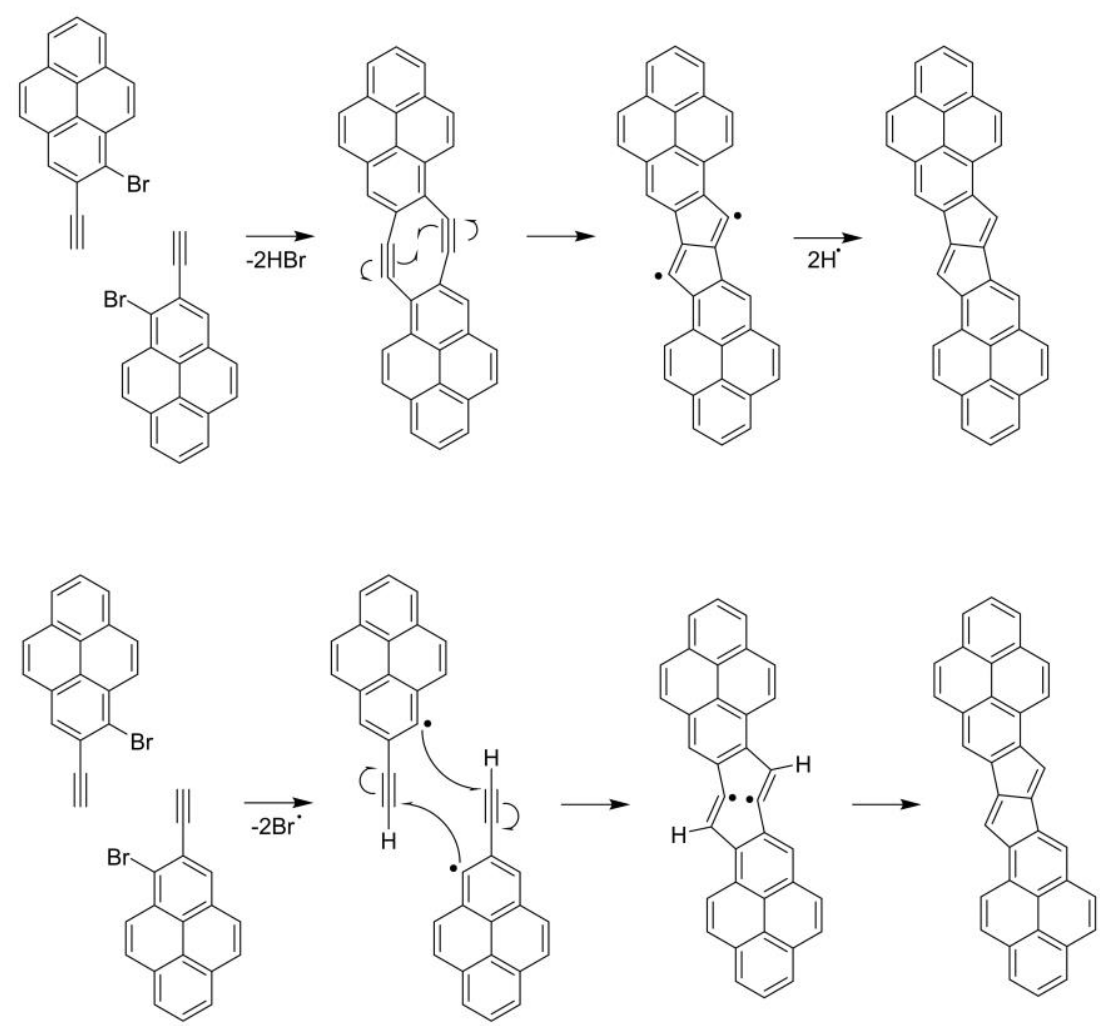

Figure S10. Two possible mechanisms for the formation of the fused dimer D3. 


\section{Control experiment to understand the effect of the $\mathrm{C}-\mathrm{Br}$ group:}

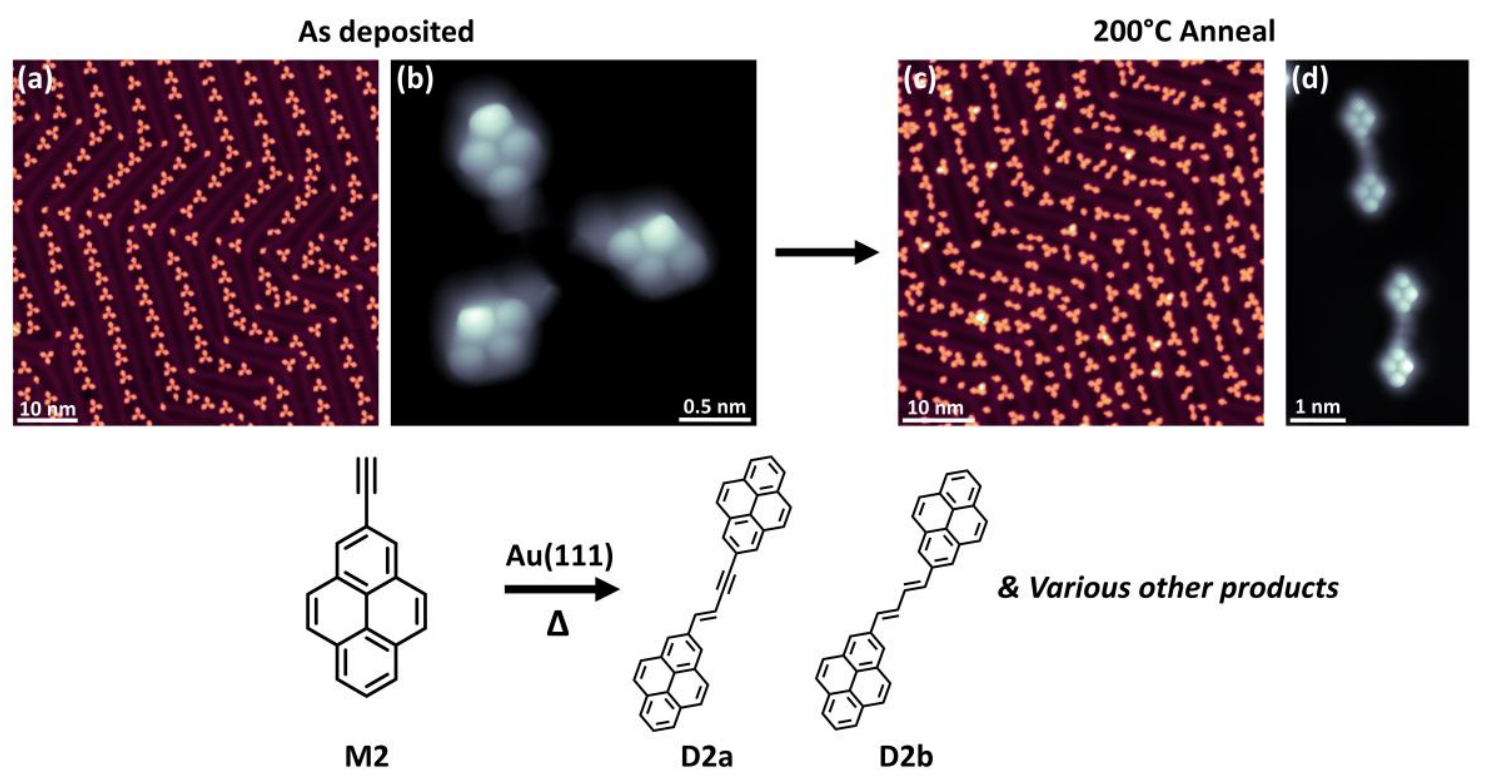

Figure S11. (a) and (b) STM images of self-assembled trimers of 2-ethynylpyrene M2 on Au(111) after deposition at room temperature. (c) and (d) STM images of the same sample after annealing to $200^{\circ} \mathrm{C}$. The only dimers observed have a clear offset in BR-STM imaging, indicating the formation of double bonds (D2a and D2b). No straight Glaser-coupled dimers were observed. The other main pathway products formed by the brominated precursor M1 (T1, T2 and T3) were also formed by M2 upon annealing, indicating that D2a can also react further to form these molecules. Imaging parameters: (a) $-0.5 \mathrm{~V}, 30 \mathrm{pA}$; (b) $5 \mathrm{mV}$, constant height; (c) $-0.5 \mathrm{~V}, 50 \mathrm{pA}$; (d) $5 \mathrm{mV}$, constant height. 


\section{Electronic properties of the products:}

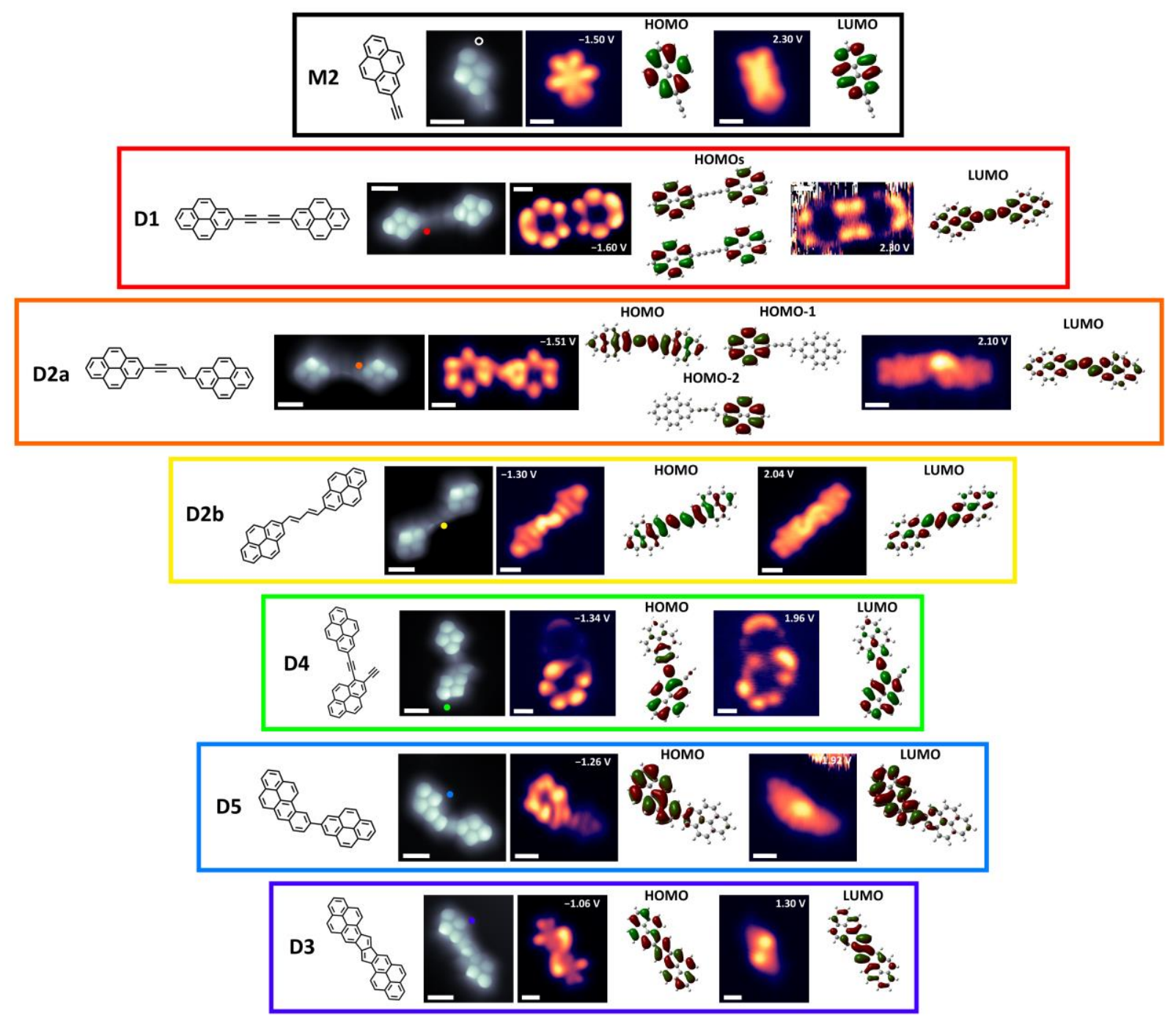

Figure S12. The chemical structures, BR-STM images, dI/dV images and DFT-calculated molecular orbitals (free standing) of all of the dimer species presented in main paper fig. 3, as well as monomer M2. Colored points mark the positions at which the spectra in main paper fig. 3(a) were recorded. In cases where the frontier orbitals are degenerate or quasi-degenerate, all are shown. For D2a, the HOMO, HOMO-1 and HOMO-2 were not degenerate, but very close in energy. The observation of a mixture of all of these orbitals in the $\mathrm{dI} / \mathrm{dV}$ imaging explains the appearance of the lobes over the pyrene sections of the molecule. The dI/dV images of D1 and D4 were recorded in constant current mode, with the rest in constant height. All $\mathrm{dI} / \mathrm{dV}$ images were recorded with a CO tip, with the exception of M2 and D3. All scale bars are 500 pm. 

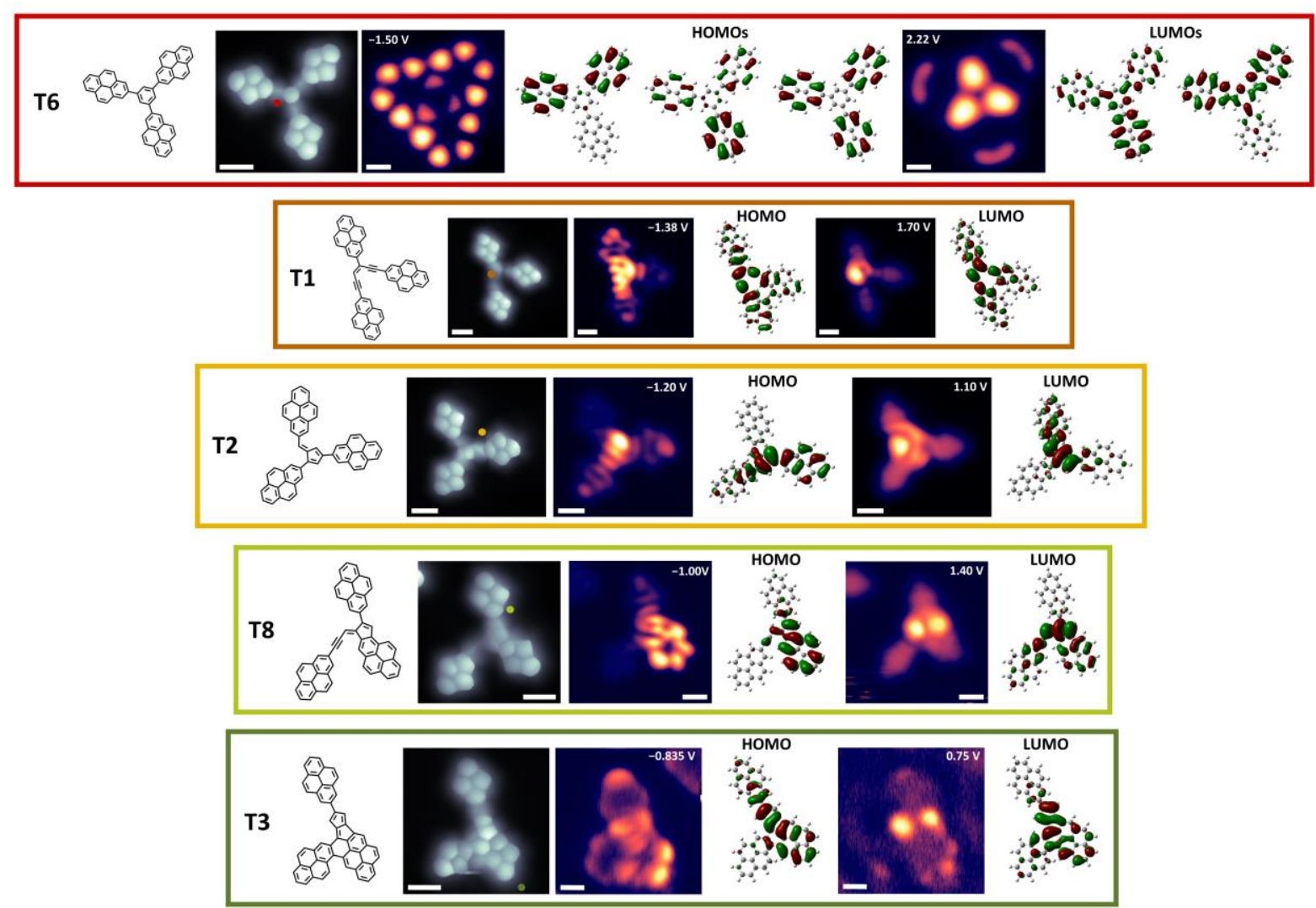

Figure S13. The chemical structures, BR-STM images, dI/dV images and DFT-calculated molecular orbitals (free standing) of all of the trimer species presented in main paper fig. 3. Colored points mark the positions at which the spectra in main paper fig. 3(b) were recorded. In cases where the frontier orbitals are degenerate or quasidegenerate, all are shown. For T6, the planarized version of the molecule with $\mathrm{D}_{3 \mathrm{~h}}$ symmetry is shown, as this is probably the more favorable conformation when adsorbed on a surface. The three highest occupied orbitals are degenerate, as are the two lowest unoccupied orbitals. The dI/dV images of T6 and $\mathbf{T 3}$ were recorded in constant current mode, with the rest in constant height. All dI/dV images were recorded with a CO tip, with the exception of T6. All scale bars are $500 \mathrm{pm}$. 


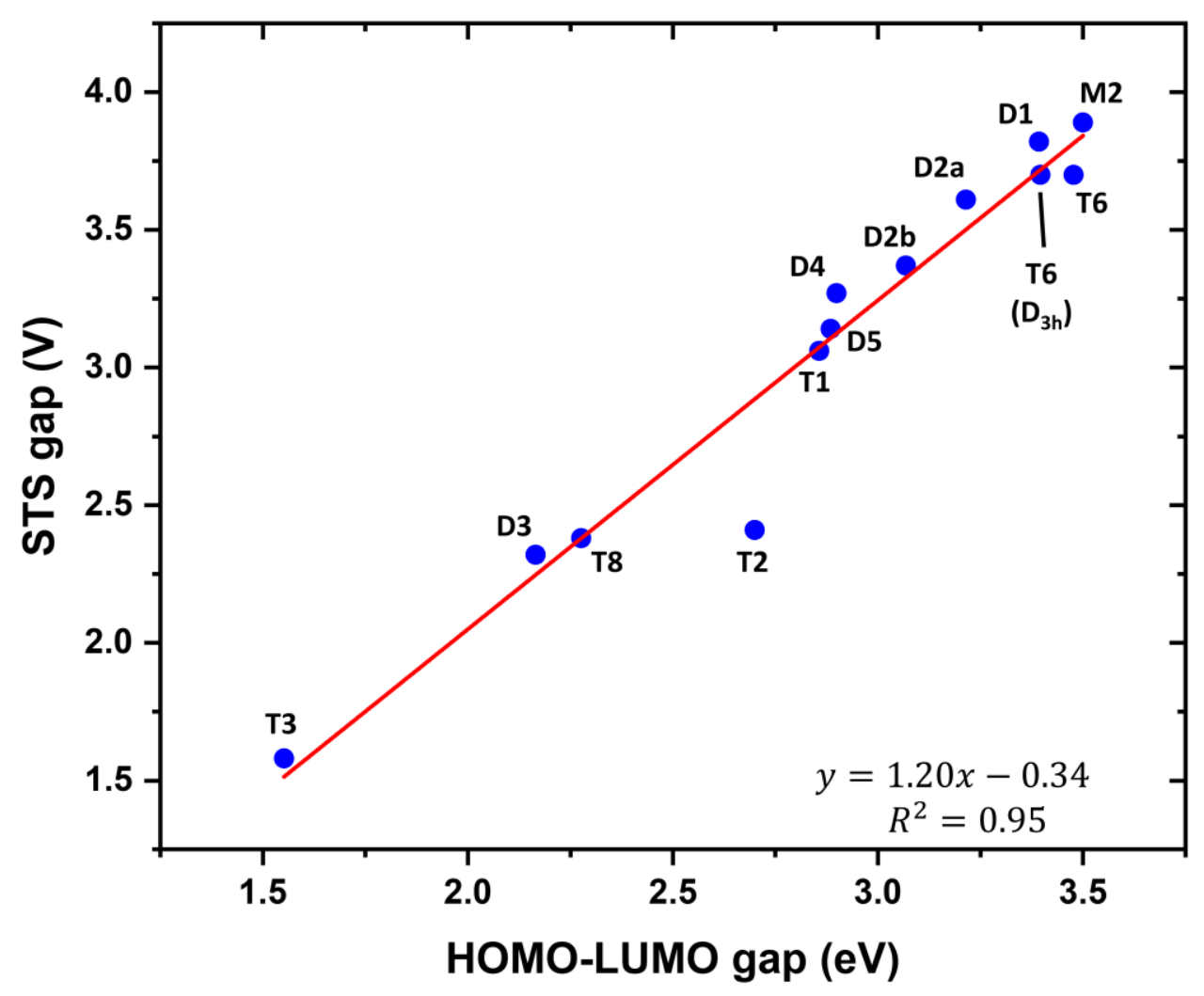

Figure S14. A plot of the measured gap (via STS) against the calculated HOMO-LUMO gap (via free-standing DFT). The vast majority of the measurements fit well with the linear trend. The experimental results are also negatively offset (i.e. a reduced gap) with respect to the DFT results, as expected. Both conformations of T6 are plotted: the relaxed free-standing molecule as well as the $\mathbf{T 6}$ molecule with $\mathrm{D}_{3 \mathrm{~h}}$ symmetry, constrained to a planar conformation to reflect how it may be on the surface. 


\section{Synthetic Methods}

\section{General methods for the synthesis of molecules by solution chemistry}

All reactions were carried out under argon using oven-dried glassware. $\mathrm{Et}_{3} \mathrm{~N}$ and $i$ - $\operatorname{Pr}_{2} \mathrm{NEt}_{\text {were }}$ dried and distillated from $\mathrm{CaH}_{2}$. Commercial reagents were purchased from ABCR, GmbH, Sigma-Aldrich, Inc., TCI Chemicals or Merck, Hexane, THF, DMF and $\mathrm{CH}_{2} \mathrm{Cl}_{2}$ were purified by a MBraun SPS-800 Solvent Purification System. TLC was performed on Merck silica gel $60 \mathrm{~F}_{254}$ and chromatograms were visualized with UV light (254 and $365 \mathrm{~nm}$ ). Flash column chromatography was performed on Merck silica gel 60 (ASTM 230-400 mesh). ${ }^{1} \mathrm{H}$ and ${ }^{13} \mathrm{C}$ NMR spectra were recorded at 300 and $75 \mathrm{MHz}$ (Varian Mercury 300). APCI spectra were determined on a Bruker Microtof instrument. Deuterated solvents were purchased from Acros Organics.

\section{Experimental details for the synthesis of molecule M1 and M2}

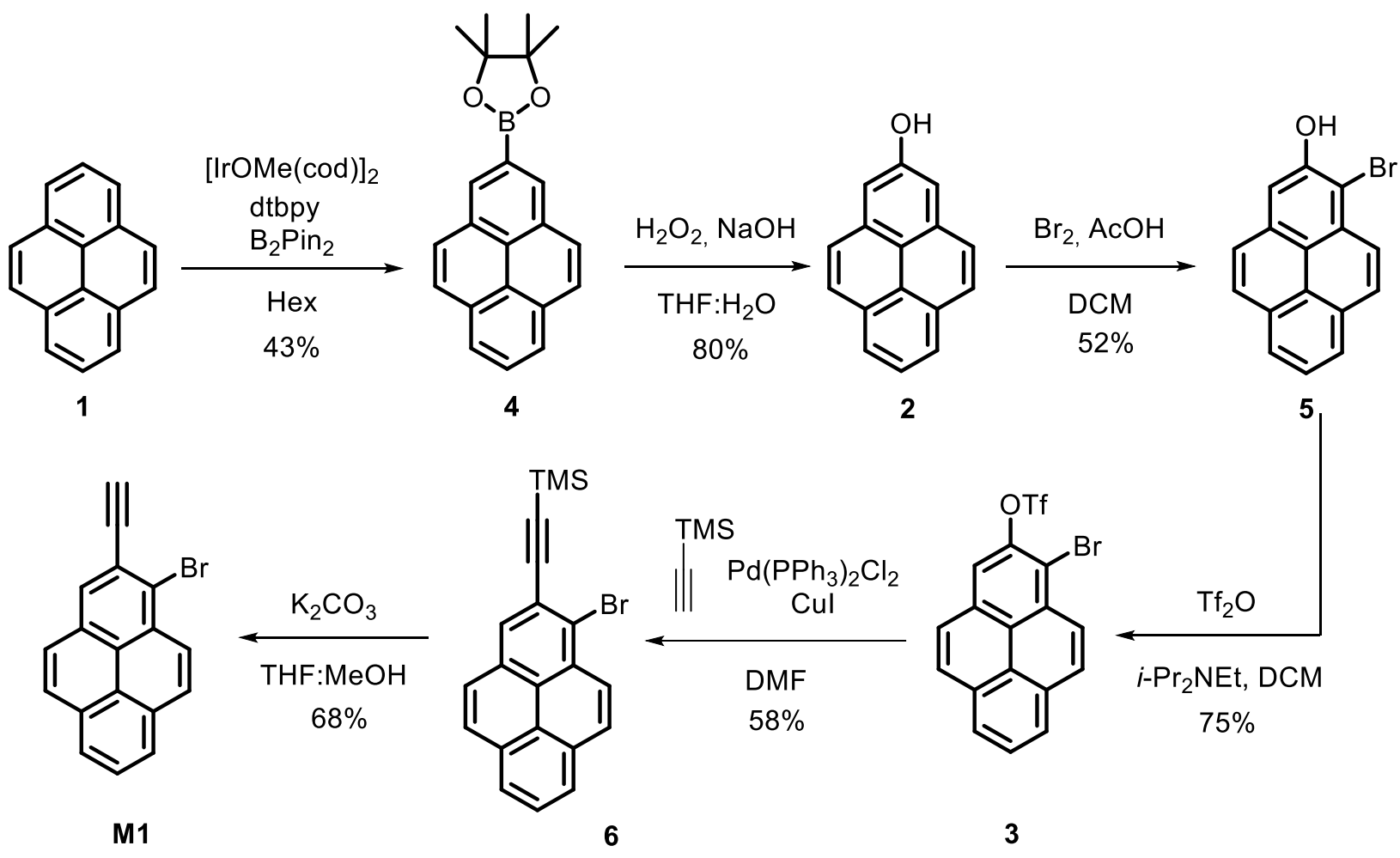

Scheme S1. Synthetic route to obtain molecule M1. 
<smiles>c1cc2ccc3cccc4ccc(c1)c2c34</smiles>

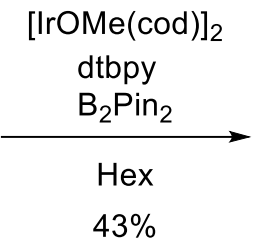

1<smiles>CC1(C)OB(c2cc3ccc4cccc5ccc(c2)c3c45)OC1(C)C</smiles>

4

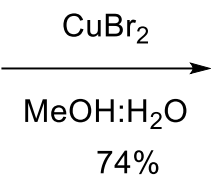

$74 \%$<smiles>Brc1cc2ccc3cccc4ccc(c1)c2c34</smiles>

7

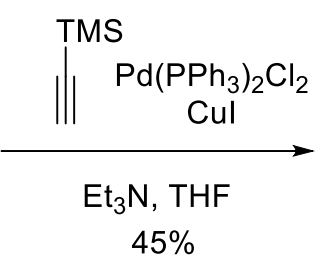<smiles>c1cc2c3c(cccc3c1)CCC2</smiles>

8<smiles>C#Cc1cc2ccc3cccc4ccc(c1)c2c34</smiles><smiles>O=C([O-])[C@H](O[Na])[N+]([O-])([O-])[O-]</smiles>

$60 \%$

M2

Scheme S2. Synthetic route to obtain molecule M2.

\subsection{Preparation of 4,4,5,5-tetramethyl-2-(pyren-2-yl)-1,3,2-dioxaborolane (4)}<smiles>c1cc2ccc3cccc4ccc(c1)c2c34</smiles>

1<smiles>CC1(C)OBOC1(C)C</smiles>

$[\operatorname{lrOMe}(\operatorname{cod})]_{2}$ dtbpy $\mathrm{B}_{2} \mathrm{Pin}_{2}$

Hex

$43 \%$<smiles>[O]c1cc2ccc3cccc4ccc(c1)c2c34</smiles>

4

Scheme S3. Synthesis of compound 4.

Pyrene 1 (500 mg, $2.47 \mathrm{mmol}),\left[\{\operatorname{Ir}(\mu-\mathrm{OMe})(\operatorname{cod})\}_{2}\right](17.0 \mathrm{mg}, 25.0 \mu \mathrm{mol})$ and 4,4`-di-tert-butyl-2,2‘-dipyridine $(13.0 \mathrm{mg}, 48.4 \mu \mathrm{mol})$ were suspended in hexane $(20 \mathrm{ml})$ in a sealed tube. A solution of bis(pinacolato)diboron $(596 \mathrm{mg}, 2.35 \mathrm{mmol})$ in hexane $(30 \mathrm{ml})$ was added dropwise to the suspension during $1 \mathrm{~h}$ at $80{ }^{\circ} \mathrm{C}$. The reaction mixture was stirred for $16 \mathrm{~h}$ at $80^{\circ} \mathrm{C}$ and then filtered through a short plug of silica using $\mathrm{CH}_{2} \mathrm{Cl}_{2}$ as eluent. The solvent was removed under reduced pressure and the residue was purified by flash column chromatography $\left(\mathrm{SiO}_{2}\right.$, $\mathrm{CH}_{2} \mathrm{Cl}_{2} /$ Hexane, 1:1), to afford 4 (374 $\left.\mathrm{mg}, 43 \%\right)$ as a colorless solid.

${ }^{1}$ H NMR $\left(300 \mathrm{MHz}, \mathrm{CDCl}_{3}\right) \delta: 8.67(\mathrm{~s}, 2 \mathrm{H}), 8.17(\mathrm{~d}, J=8.0 \mathrm{~Hz}, 2 \mathrm{H}), 8.11(\mathrm{~d}, J=9.0 \mathrm{~Hz}, 2 \mathrm{H}), 8.06(\mathrm{~d}, J=9.0$ $\mathrm{Hz}, 2 \mathrm{H}), 8.02$ (t, $J=8.0 \mathrm{~Hz}, 1 \mathrm{H}), 1.49(\mathrm{~s}, 12 \mathrm{H}) \mathrm{ppm}^{7}$ 


\subsection{Preparation of pyren-2-ol (2)}<smiles></smiles>

4<smiles></smiles>

2

Scheme S4. Synthesis of compound 2.

Compound 4 (435 mg, $1.33 \mathrm{mmol})$ and $\mathrm{NaOH}(160 \mathrm{mg}, 3.98 \mathrm{mmol})$ were dissolved in THF: $\mathrm{H}_{2} \mathrm{O}(10: 1,46 \mathrm{~mL})$. An aqueous solution of $\mathrm{H}_{2} \mathrm{O}_{2}(135 \mathrm{mg}, 4.0 \mathrm{mmol}, 33 \mathrm{wt} \%)$ was added dropwise to the previous mixture. After stirring for $4 \mathrm{~h}$, the solution was acidified to $\mathrm{pH} 1-2$ by using $\mathrm{HCl} 1 \mathrm{M}$. The reaction mixture was extracted with $\mathrm{Et}_{2} \mathrm{O}(3 \times 25 \mathrm{~mL})$. The organic fractions were dried over $\mathrm{MgSO}_{4}$ and the solvent was removed under reduced pressure. The crude mixture was purified by column chromatography $\left(\mathrm{SiO}_{2}\right.$, hexane/ $\left.\mathrm{CH}_{2} \mathrm{Cl}_{2} / \mathrm{Et}_{2} \mathrm{O}, 2: 1: 1\right)$, to isolate the alcohol $2(232 \mathrm{mg}, 80 \%)$ as a light-brown solid.

${ }^{1}$ H NMR $(300 \mathrm{MHz}$, Acetone[D 6 ]) $\delta: 9.01(\mathrm{~s}, 1 \mathrm{H}), 8.18(\mathrm{~d}, J=8.0 \mathrm{~Hz}, 2 \mathrm{H}), 8.08(\mathrm{~d}, J=9.0 \mathrm{~Hz}, 2 \mathrm{H}), 8.01(\mathrm{~d}, J$ $=9.0 \mathrm{~Hz}, 2 \mathrm{H}), 7.92(\mathrm{t}, J=8.5 \mathrm{~Hz}, 1 \mathrm{H}), 7.77(\mathrm{~s}, 2 \mathrm{H}) \mathrm{ppm}^{8}{ }^{8}$

\subsection{Preparation of 1-bromopyren-2-ol (5)}<smiles>Oc1cc2ccc3cccc4ccc(c1)c2c34</smiles>

2

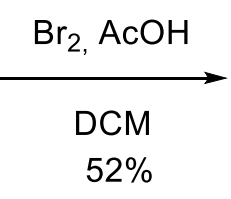<smiles>Oc1cc2ccc3cccc4ccc(c1Br)c2c34</smiles>

5

Scheme S5. Synthesis of compound 5.

Alcohol 2 (400 mg, $1.83 \mathrm{mmol})$ was dissolved in a mixture of $\mathrm{CH}_{2} \mathrm{Cl}_{2}(15 \mathrm{~mL})$ and acetic acid $(26 \mathrm{~mL})$. A solution of $\mathrm{Br}_{2}(75 \mu \mathrm{L}, 1.46 \mathrm{mmol})$ in acetic acid $(10 \mathrm{~mL})$ was added dropwise at $0{ }^{\circ} \mathrm{C}$ with vigorous stirring. The mixture was then stirred at room temperature for $30 \mathrm{~min}$. Cold water $(20 \mathrm{~mL})$ was added. The organic phase was separated and the aqueous phase was extracted with $\mathrm{CH}_{2} \mathrm{Cl}_{2}(3 \times 7 \mathrm{~mL})$. The combined organic phases were dried over $\mathrm{MgSO}_{4}$. The solvent was evaporated under reduced pressure and the residue was purified by column chromatography $\left(\mathrm{SiO}_{2}\right.$; hexane/ $\left.\mathrm{CH}_{2} \mathrm{Cl}_{2} / \mathrm{Et}_{2} \mathrm{O}, 20: 4: 3\right)$, to afford $\mathbf{5}(283 \mathrm{mg}, 52 \%)$ as a white solid.

${ }^{1} \mathbf{H}$ NMR $\left(300 \mathrm{MHz}, \mathrm{CDCl}_{3}\right) \delta: 8.28(\mathrm{~m}, 1 \mathrm{H}), 8.23-8.10(\mathrm{~m}, 3 \mathrm{H}), 8.08-7.86(\mathrm{~m}, 3 \mathrm{H}), 7.80(\mathrm{~d}, J=1.5 \mathrm{~Hz}, 1 \mathrm{H})$, 6.11 (s, 1H) ppm. ${ }^{13} \mathbf{C}$ NMR $\left(75 \mathrm{MHz}, \mathrm{CDCl}_{3}\right) \delta: 150.38,131.85,130.37,130.15,129.66,128.48,126.43,126.07$, 125.88, 125.49, 125.00, 123.89, 111.57, 108.00 ppm. EM (APCI (M+1)): 296.99. 
<smiles>Oc1cc2ccc3cccc4ccc(c1Br)c2c34</smiles>

5

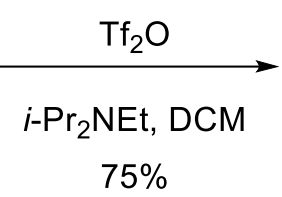

$75 \%$

Scheme S6. Synthesis of compound 3 .<smiles>Brc1cc2ccc3cccc4ccc(c1Br)c2c34</smiles>

3

Compound 5 (145 mg, $0.49 \mathrm{mmol}$ ) was dissolved in a mixture of $i-\mathrm{Pr}_{2} \mathrm{NEt}(8 \mathrm{~mL})$ and $\mathrm{CH}_{2} \mathrm{Cl}_{2}(8 \mathrm{~mL})$. Then, $\mathrm{Tf}_{2} \mathrm{O}$ $(167 \mu \mathrm{L}, 0.98 \mathrm{mmol})$ was added dropwise at $0{ }^{\circ} \mathrm{C}$ and the reaction mixture was stirred for $15 \mathrm{~min}$ at $0{ }^{\circ} \mathrm{C}$. The mixture was stirred at room temperature for $1 \mathrm{~h}$. The reaction mixture was quenched with a saturated aqueous solution of $\mathrm{NaHCO}_{3}(5 \mathrm{~mL})$. The organic phase was separated and the aqueous phase was extracted with $\mathrm{CH}_{2} \mathrm{Cl}_{2}$ $(3 \times 5 \mathrm{~mL})$. The combined organic phases were dried over $\mathrm{MgSO}_{4}$. The solvent was evaporated under reduced pressure and the crude mixture purified by column chromatography $\left(\mathrm{SiO}_{2}\right.$, hexane/ $\left.\mathrm{CH}_{2} \mathrm{Cl}_{2}, 4: 1\right)$ to afford 3 (157 $\mathrm{mg}, 75 \%)$ as a white solid.

${ }^{1} \mathbf{H}$ NMR $\left(300 \mathrm{MHz}, \mathrm{CDCl}_{3}\right) \delta: 8.41(\mathrm{~m}, 1 \mathrm{H}), 8.30-8.21(\mathrm{~m}, 3 \mathrm{H}), 8.20-8.09(\mathrm{~m}, 2 \mathrm{H}), 8.07(\mathrm{~d}, J=5.3 \mathrm{~Hz}, 1 \mathrm{H})$, $7.97(\mathrm{~m}, 1 \mathrm{H}) \mathrm{ppm} .{ }^{13} \mathrm{C}$ NMR $\left(75 \mathrm{MHz}, \mathrm{CDCl}_{3}\right) \delta: 131.73,131.29,130.91,130.63,130.56,129.50,127.17,126.80$, 126.59, 126.34, 126.06, 125.80, 123.16, 117.11, 112.46, 110.00 ppm. EM (APCI (M+1)) $\mathbf{H R}$ for $\mathrm{C}_{17} \mathrm{H}_{8} \mathrm{BrF}_{3} \mathrm{O}_{3} \mathrm{~S}$ calcd: 427.9324, found: 427.9322 .

\subsection{Preparation of ((1-bromopyren-2-yl)ethynyl)trimethylsilane (6)}<smiles>Brc1cc2ccc3cccc4ccc(c1Br)c2c34</smiles>

3

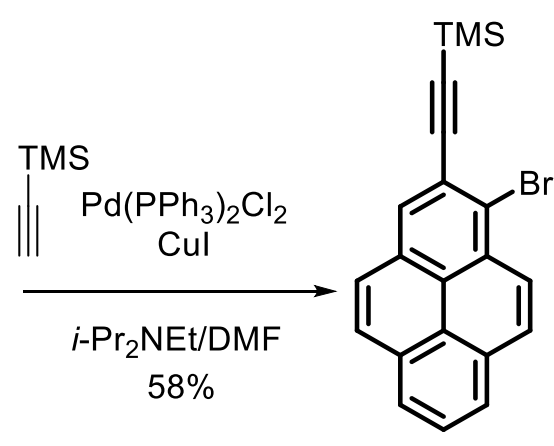

6

Scheme S7. Synthesis of compound 6.

Compound 3 (140 mg, $0.33 \mathrm{mmol}), \mathrm{Pd}\left(\mathrm{PPh}_{3}\right)_{2} \mathrm{Cl}_{2}(23 \mathrm{mg}, 0.033 \mathrm{mmol})$ and $\mathrm{CuI}(7.0 \mathrm{mg}, 0.033 \mathrm{mmol})$ were dissolved in a mixture of $i$ - $\operatorname{Pr}_{2} \mathrm{NEt} / \mathrm{DMF}(1: 1,4 \mathrm{~mL})$. Then, trimethylsilylacetylene $(67 \mu \mathrm{L}, 0.49 \mathrm{mmol})$ was added and the reaction mixture was stirred at room temperature for $16 \mathrm{~h}$. The solvent was evaporated under reduced pressure and the residue purified by column chromatography $\left(\mathrm{SiO}_{2}\right.$, hexane/ $\left.\mathrm{CH}_{2} \mathrm{Cl}_{2}, 4: 1\right)$, to isolate compound 6 (72 mg, $58 \%$ ) as a white solid. 
${ }^{1} \mathbf{H}$ NMR $\left(300 \mathrm{MHz}, \mathrm{CDCl}_{3}\right) \delta: 8.51(\mathrm{~d}, J=9.3 \mathrm{~Hz}, 1 \mathrm{H}), 8.30(\mathrm{~s}, 1 \mathrm{H}), 8.26-8.14(\mathrm{~m}, 3 \mathrm{H}), 8.05(\mathrm{~m}, 2 \mathrm{H}), 7.95(\mathrm{~d}$, $J=9.0 \mathrm{~Hz}, 1 \mathrm{H}), 0.37(\mathrm{~s}, 9 \mathrm{H}) \mathrm{ppm} .{ }^{13} \mathbf{C} \mathbf{~ N M R}\left(75 \mathrm{MHz}, \mathrm{CDCl}_{3}\right) \delta: 131.17,130.88,128.48,128.19,128.03,127.96$, $126.83,126.66,126.28,125.45,125.27,124.24,120.36,105.68,94.57,0.07 \mathrm{ppm}$.

2.6. Preparation of 1-bromo-2-ethynylpyrene (M1)<smiles></smiles>

Scheme S8. Synthesis of compound M1.

Compound 6 (60 mg, $0.16 \mathrm{mmol}$ and $\mathrm{K}_{2} \mathrm{CO}_{3}(131 \mathrm{mg}, 0.95 \mathrm{mmol})$ were suspended in a mixture of THF/MeOH $(1: 1,2 \mathrm{~mL})$. The mixture was stirred at room temperature for $16 \mathrm{~h}$. Then, $\mathrm{H}_{2} \mathrm{O}(3 \mathrm{~mL})$ was added to the mixture and extracted with $\mathrm{CH}_{2} \mathrm{Cl}_{2}(3 \times 3 \mathrm{~mL})$. The combined organic phases were dried over $\mathrm{MgSO}_{4}$. The solvent was evaporated under reduced pressure and the residue purified by column chromatography $\left(\mathrm{SiO}_{2}\right.$, hexane), to isolate the product M1 (33 mg, $68 \%$ ) as a white solid.

${ }^{1} \mathbf{H}$ NMR $\left(300 \mathrm{MHz}, \mathrm{CDCl}_{3}\right) \delta: 8.47(\mathrm{~m}, 1 \mathrm{H}), 8.29(\mathrm{~s}, 1 \mathrm{H}), 8.23-8.13(\mathrm{~m}, 3 \mathrm{H}), 8.09-8.00(\mathrm{~m}, 2 \mathrm{H}), 7.93(\mathrm{~d}, J=$ $9.0 \mathrm{~Hz}, 1 \mathrm{H}), 3.56(\mathrm{~s}, 1 \mathrm{H}) \mathrm{ppm}{ }^{13} \mathbf{C} \mathbf{~ N M R}\left(75 \mathrm{MHz}, \mathrm{CDCl}_{3}\right) \delta: 131.31,130.89,129.99,129.55,129.35,128.35$, $127.02,126.50,126.40,126.07,125.87,122.46,81.91 \mathrm{ppm}$.

\subsection{Preparation of 2-bromopyrene (7)}<smiles>CC1(C)OB(c2cc3ccc4cccc5ccc(c2)c3c45)OC1(C)C</smiles>

4<smiles>Brc1cc2ccc3cccc4ccc(c1)c2c34</smiles>

7

Scheme S9. Synthesis of compound 7. 
Compound 4 (390 mg, $1.19 \mathrm{mmol})$ and $\mathrm{CuBr}_{2}(795 \mathrm{mg}, 3.57 \mathrm{mmol})$ were dissolved in a mixture of $\mathrm{MeOH}: \mathrm{H}_{2} \mathrm{O}$ $(1: 1,24 \mathrm{~mL})$. The reaction mixture was stirred under reflux for $16 \mathrm{~h}$. Once cooled to room temperature, $\mathrm{H}_{2} \mathrm{O}(40$ $\mathrm{ml}$ ) was added and the mixture extracted with $\mathrm{CH}_{2} \mathrm{Cl}_{2}(2 \times 20 \mathrm{~mL})$. The combined organic phases were dried over $\mathrm{MgSO}_{4}$, the solvent was evaporated under reduced pressure and the residue purified by column chromatography $\left(\mathrm{SiO}_{2}\right.$, hexane/ $\left.\mathrm{CH}_{2} \mathrm{Cl}_{2}, 15: 1\right)$, to isolate 2-bromopyrene $7(247 \mathrm{mg}, 74 \%)$ as a white solid.

${ }^{1} \mathbf{H}$ NMR $\left(300 \mathrm{MHz}, \mathrm{CDCl}_{3}\right) \delta: 8.26(\mathrm{~s}, 2 \mathrm{H}), 8.20(\mathrm{~d}, J=8.0 \mathrm{~Hz}, 2 \mathrm{H}), 8.08(\mathrm{~d}, J=9.0 \mathrm{~Hz}, 2 \mathrm{H}), 8.00(\mathrm{t}, J=8.0$ $\mathrm{Hz}, 1 \mathrm{H}), 7.90 \mathrm{ppm}(\mathrm{d}, J=9.0 \mathrm{~Hz}, 2 \mathrm{H}) \mathrm{ppm}^{7}$

\subsection{Preparation of trimethyl(pyren-2-ylethynyl)silane (8)}<smiles>Brc1cc2ccc3cccc4ccc(c1)c2c34</smiles>

7

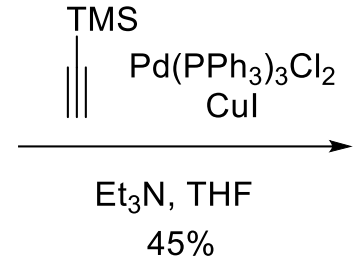

Scheme S10. Synthesis of compound 8

Compound 7 (148 mg, $0.53 \mathrm{mmol}), \mathrm{Pd}\left(\mathrm{PPh}_{3}\right)_{2} \mathrm{Cl}_{2}(19 \mathrm{mg}, 0.03 \mathrm{mmol})$ and $\mathrm{CuI}(7 \mathrm{mg}, 0.03 \mathrm{mmol})$ were dissolved in a mixture of $\mathrm{Et}_{3} \mathrm{~N} / \mathrm{THF}(2.5: 1,18 \mathrm{~mL})$. Then, trimethylsilylacetylene $(81 \mu \mathrm{L}, 0.58 \mathrm{mmol})$ was added and the reaction mixture was stirred under reflux for $16 \mathrm{~h}$. The solvent was evaporated under reduced pressure and the crude purified by column chromatography $\left(\mathrm{SiO}_{2}\right.$, hexane $\left./ \mathrm{CH}_{2} \mathrm{Cl}_{2}, 50: 1\right)$, to afford $\mathbf{8}(40 \mathrm{mg}, 45 \%)$ as a white solid.

${ }^{1}$ H NMR $\left(300 \mathrm{MHz}, \mathrm{CDCl}_{3}\right) \delta: 8.32(\mathrm{~s}, 2 \mathrm{H}), 8.20(\mathrm{~d}, J=8.0 \mathrm{~Hz}, 2 \mathrm{H}), 8.10(\mathrm{~d}, J=8.0 \mathrm{~Hz}, 2 \mathrm{H}), 7.90-8.09$ (m, 3 $\mathrm{H}), 0.26 \mathrm{ppm}(\mathrm{s}, 9 \mathrm{H}) \mathrm{ppm}^{7}$ 


\subsection{Preparation of 2-ethynylpyrene (M2)}<smiles>CS(=O)(=O)C#Cc1cc2ccc3cccc4ccc(c1)c2c34</smiles>

8

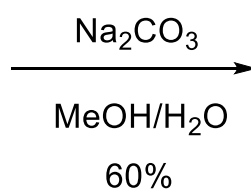

$60 \%$<smiles>C#Cc1cc2ccc3cccc4ccc(c1)c2c34</smiles>

M2

Scheme S11. Synthesis of compound M2.

Compound 8 (125 mg, $0.42 \mathrm{mmol}$ and $\mathrm{Na}_{2} \mathrm{CO}_{3}(156 \mathrm{mg}, 1.47 \mathrm{mmol})$ were suspended in a mixture of $\mathrm{MeOH} / \mathrm{H}_{2} \mathrm{O}$ $(10: 1,38 \mathrm{~mL})$. The mixture was then stirred for $16 \mathrm{~h}$. Then, $\mathrm{H}_{2} \mathrm{O}(10 \mathrm{~mL})$ was added to the mixture and the aqueous phase was extracted with $\mathrm{CH}_{2} \mathrm{Cl}_{2}(3 \times 20 \mathrm{~mL})$. The combined organic phases were dried over $\mathrm{MgSO}_{4}$. The solvent was evaporated under reduced pressure and the crude purified by column chromatography $\left(\mathrm{SiO}_{2}\right.$, hexane $\left./ \mathrm{CH}_{2} \mathrm{Cl}_{2}, 10: 1\right)$, to isolate $\mathbf{M 2}(58 \mathrm{mg}, 60 \%)$ as a white solid.

${ }^{1} \mathbf{H}$ NMR $\left(300 \mathrm{MHz}^{\mathrm{CDCl}} 3\right) \delta: 8.36(\mathrm{~s}, 2 \mathrm{H}), 8.24(\mathrm{~d}, J=8.0 \mathrm{~Hz}, 2 \mathrm{H}), 8.09(\mathrm{~d}, J=8.0 \mathrm{~Hz}, 2 \mathrm{H}), 7.95-8.12(\mathrm{~m}, 3$ $\mathrm{H}), 3.21 \mathrm{ppm}(\mathrm{s}, 1 \mathrm{H}) \mathrm{ppm}^{7}$ 


\section{NMR SPECTRA}<smiles>Oc1cc2ccc3cccc4ccc(c1Br)c2c34</smiles>
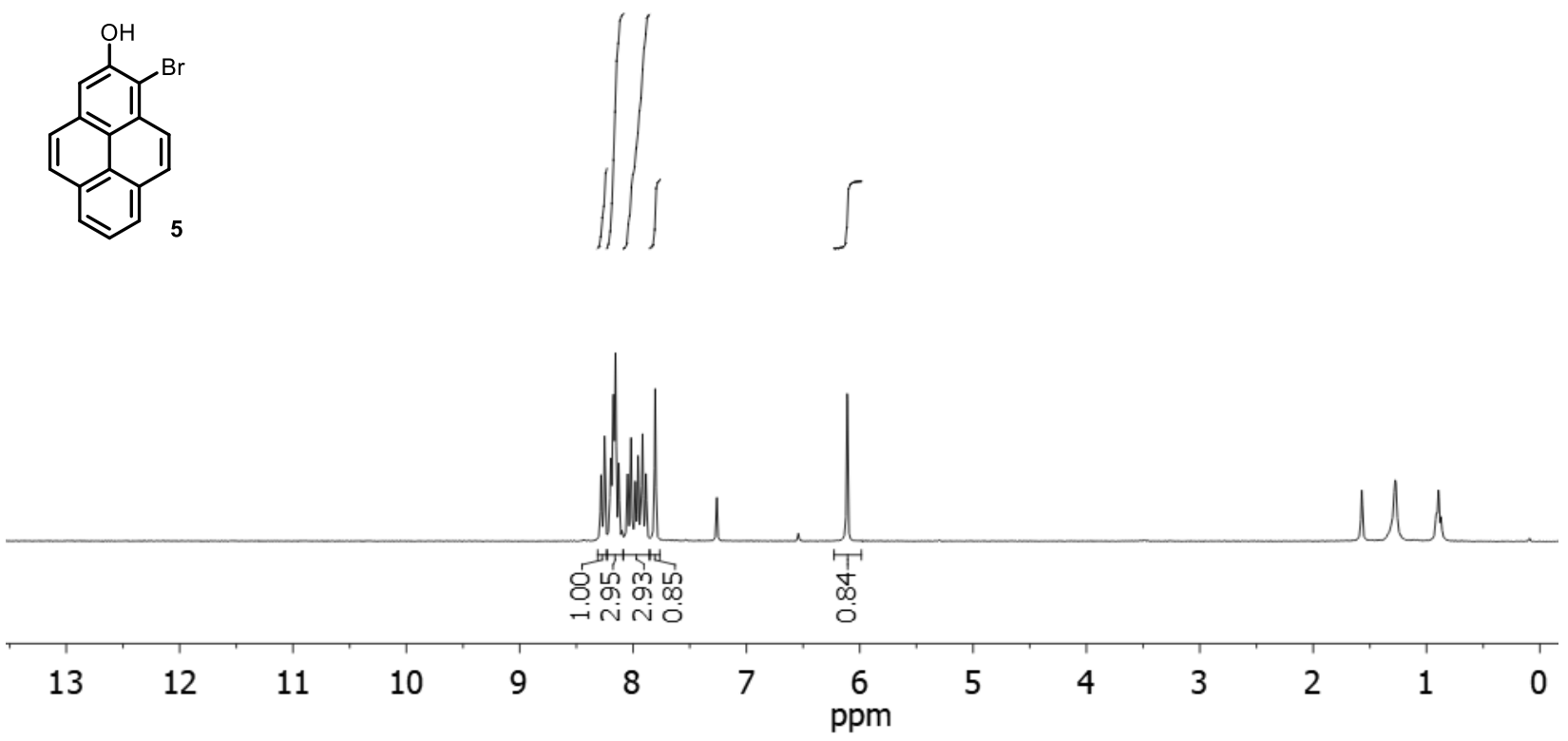

Figure S15. ${ }^{1} \mathrm{H}-\mathrm{NMR}$ spectrum of 5.
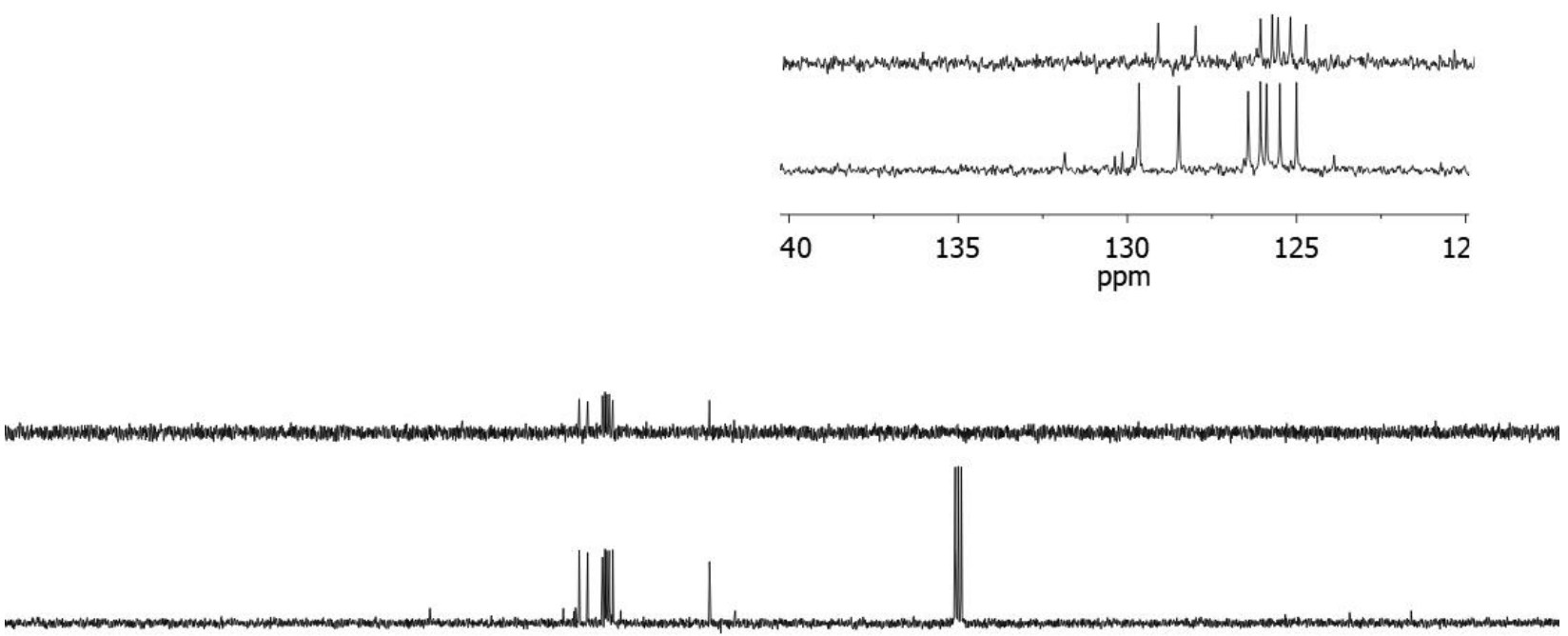

$\begin{array}{llllllllllllllllllllll}0 & 200 & 190 & 180 & 170 & 160 & 150 & 140 & 130 & 120 & 110 & \begin{array}{c}100 \\ \mathrm{ppm}\end{array} & 90 & 80 & 70 & 60 & 50 & 40 & 30 & 20 & 10 & 0\end{array}$

Figure S16. ${ }^{13} \mathrm{C}-\mathrm{NMR}$ and DEPT-135 spectra of 5. 


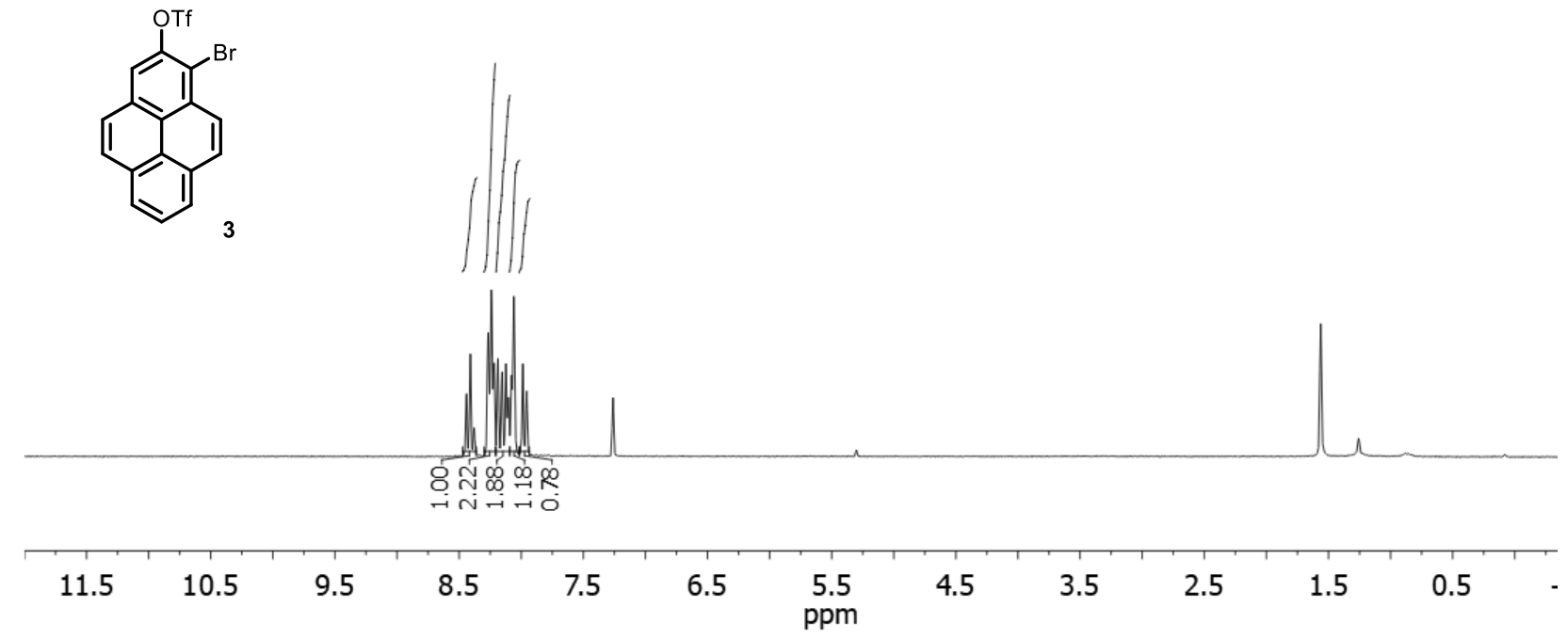

Figure S17. ${ }^{1} \mathrm{H}-\mathrm{NMR}$ spectrum of $\mathbf{3}$.
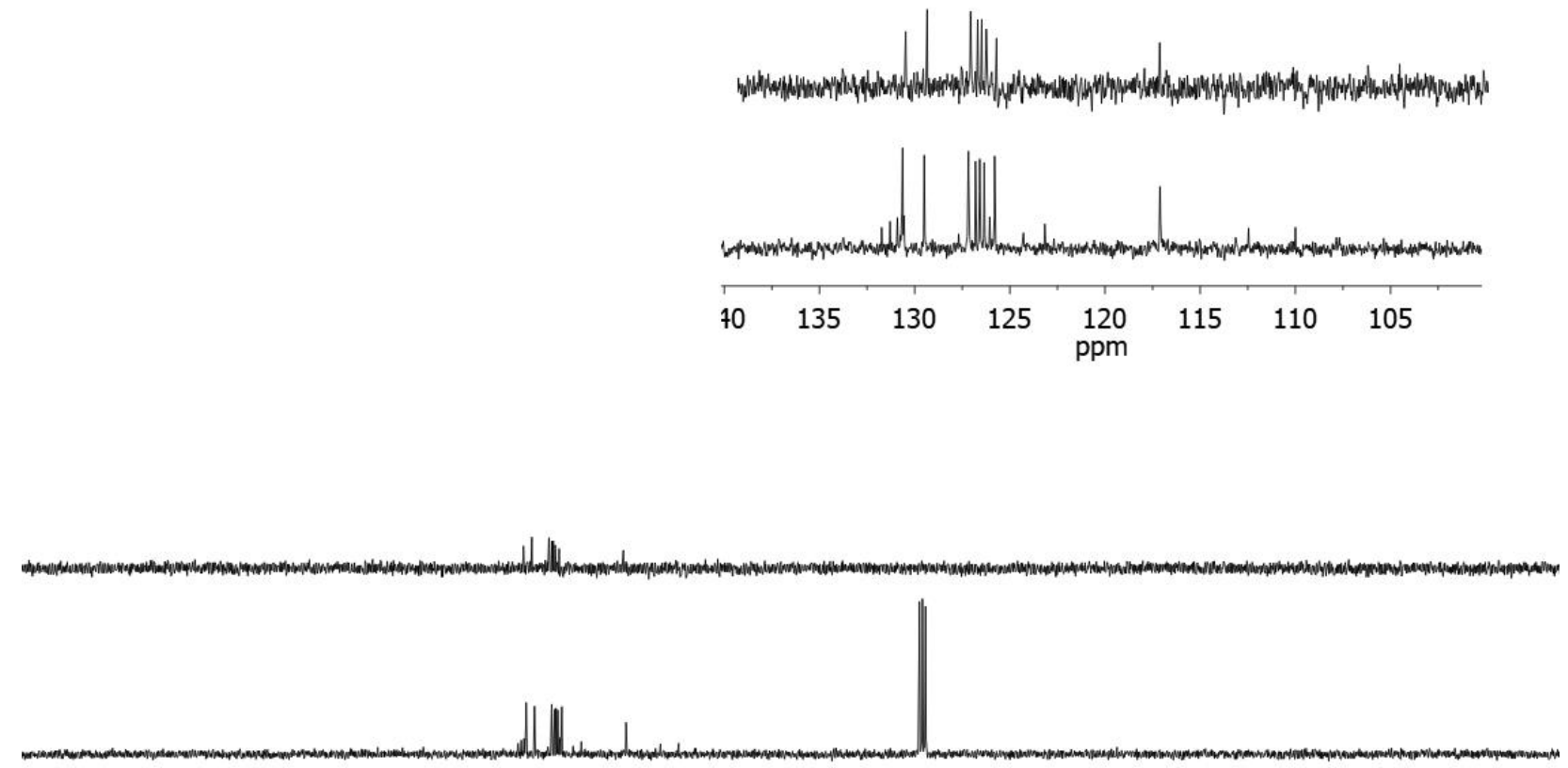

$\begin{array}{llllllllllllllllllllll}0 & 190 & 180 & 170 & 160 & 150 & 140 & 130 & 120 & 110 & \begin{array}{c}100 \\ \mathrm{ppm}\end{array} & 90 & 80 & 70 & 60 & 50 & 40 & 30 & 20 & 10 & 0 & -\end{array}$

Figure S18. ${ }^{13} \mathrm{C}-\mathrm{NMR}$ and DEPT-135 spectra of $\mathbf{3}$. 
<smiles>CC#Cc1cc2ccc3cccc4ccc(c1Br)c2c34</smiles>
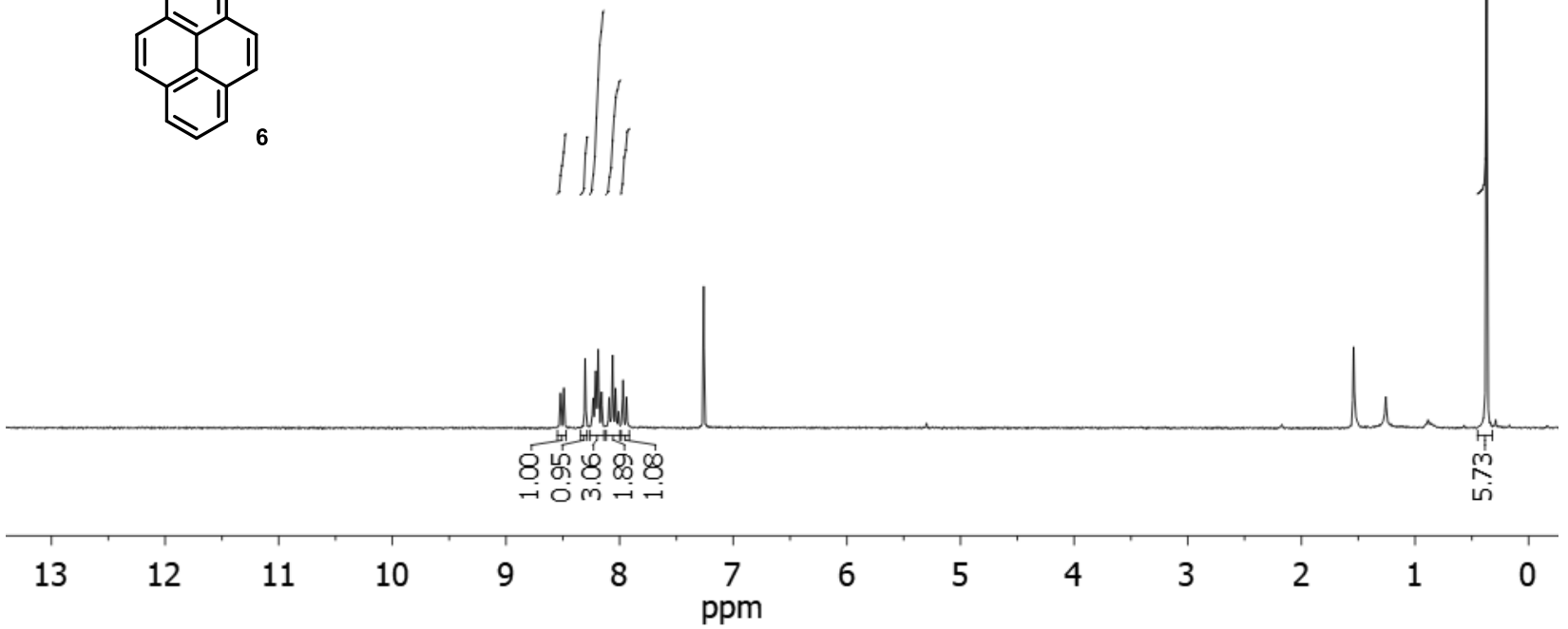

Figure S19. ${ }^{1} \mathrm{H}-\mathrm{NMR}$ spectrum of 6.
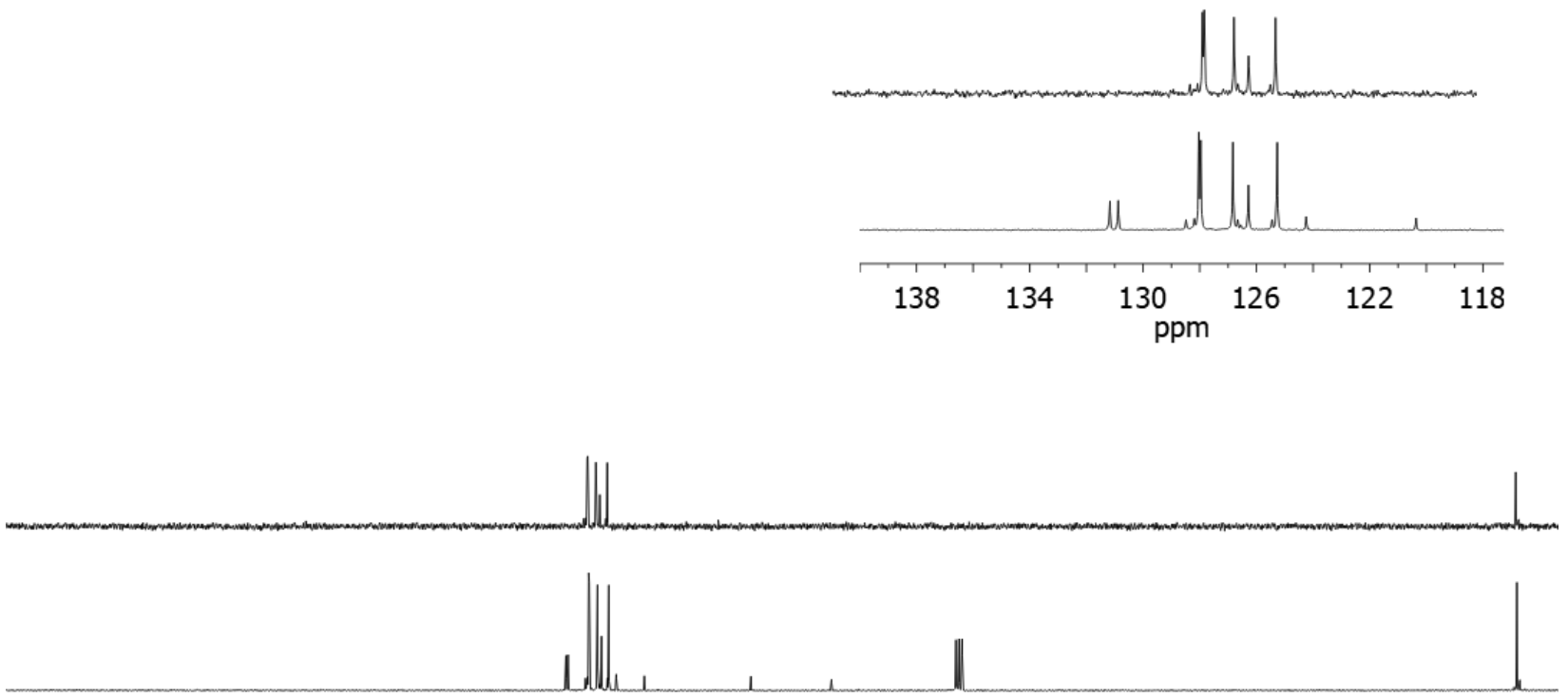

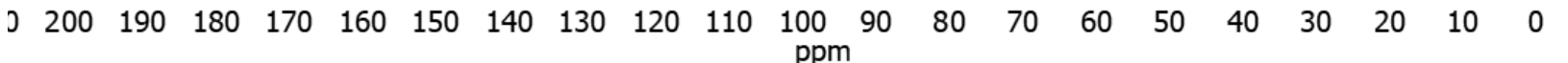

Figure S20. ${ }^{13} \mathrm{C}-\mathrm{NMR}$ and DEPT-135 spectra of $\mathbf{6}$. 
<smiles></smiles>

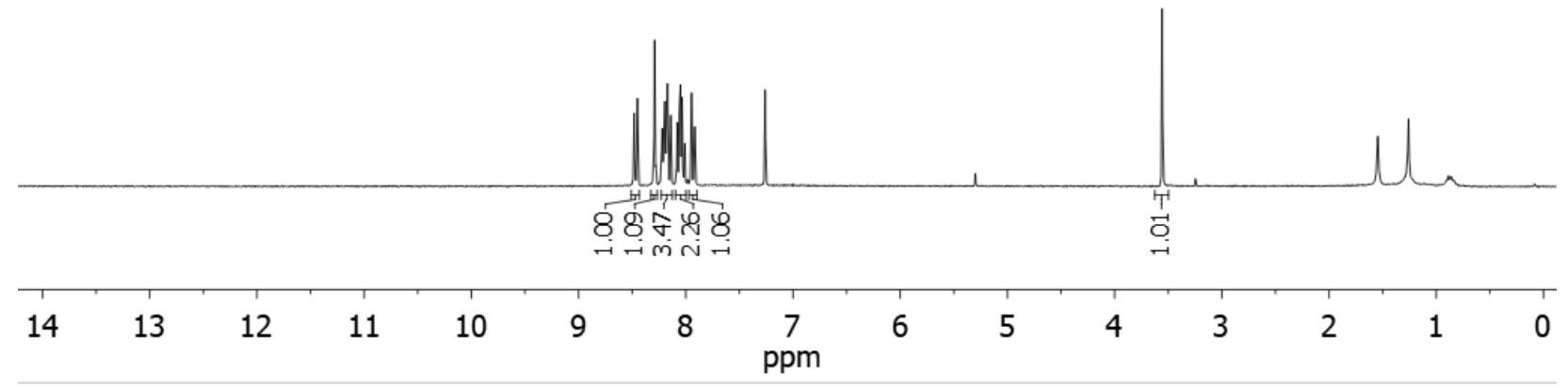

Figure S21. ${ }^{1} \mathrm{H}-\mathrm{NMR}$ spectrum of M1.
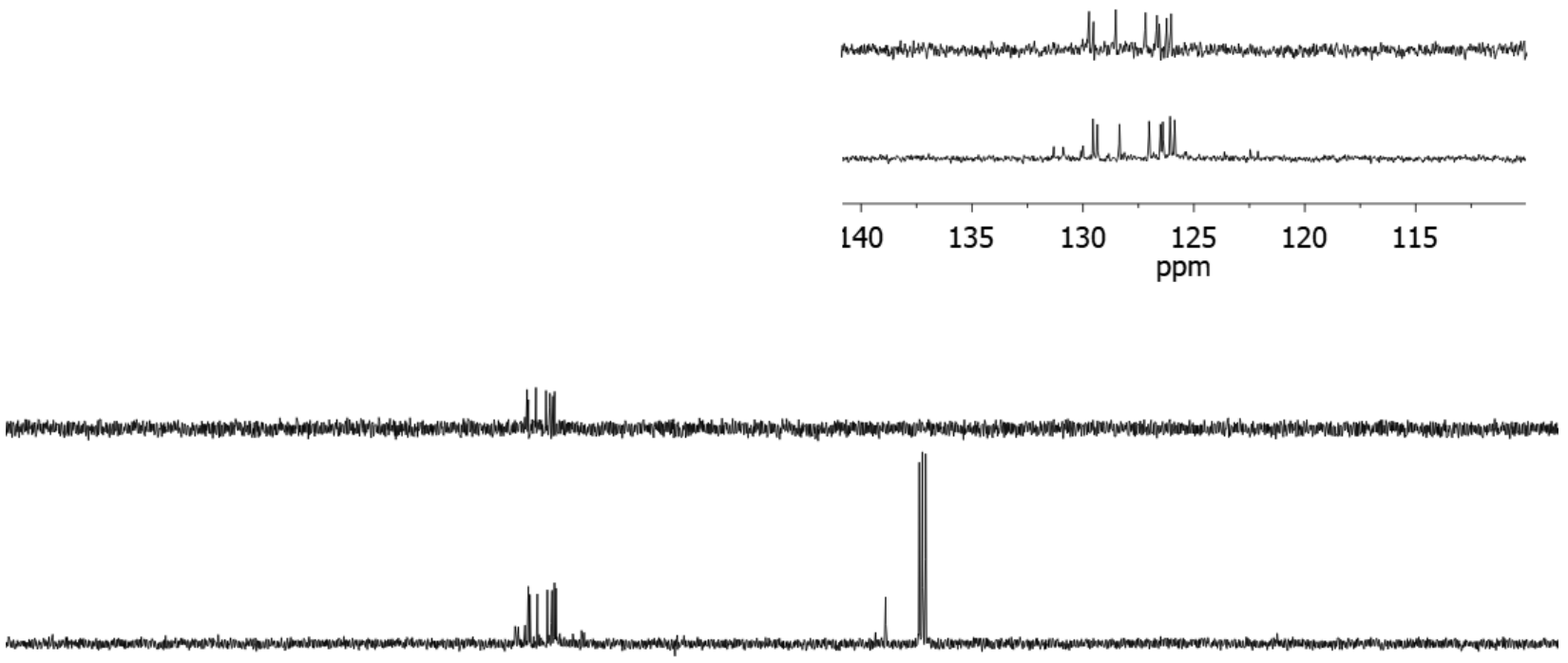

\begin{tabular}{llllllllllllllllllllllllllll}
\hline 0 & 190 & 180 & 170 & 160 & 150 & 140 & 130 & 120 & 110 & 100 & 90 & 80 & 70 & 60 & 50 & 40 & 30 & 20 & 10 & 0 &.
\end{tabular}

Figure S22. ${ }^{13} \mathrm{C}-\mathrm{NMR}$ and DEPT-135 spectra of M1. 


\section{References}

(1) Zhang, Y. Q.; Paszkiewicz, M.; Du, P.; Zhang, L.; Lin, T.; Chen, Z.; Klyatskaya, S.; Ruben, M.; Seitsonen, A. P.; Barth, J. V.; Klappenberger, F. Complex Supramolecular Interfacial Tessellation through Convergent Multi-Step Reaction of a Dissymmetric Simple Organic Precursor. Nat. Chem. 2018, 10 (3), 296-304. https://doi.org/10.1038/nchem.2924.

(2) Wang, T.; Lv, H.; Fan, Q.; Feng, L.; Wu, X.; Zhu, J. Highly Selective Synthesis of Cis-Enediynes on a Ag(111) Surface. Angew. Chem. Int. Ed. 2017, 56 (17), 4762-4766. https://doi.org/10.1002/anie.201701142.

(3) Aakeröy, C. B.; Welideniya, D.; Desper, J. Ethynyl Hydrogen Bonds and Iodoethynyl Halogen Bonds: A Case of Synthon Mimicry. CrystEngComm 2017, 19 (1), 11-13. https://doi.org/10.1039/c6ce02201d.

(4) Cavallo, G.; Metrangolo, P.; Milani, R.; Pilati, T.; Priimagi, A.; Resnati, G.; Terraneo, G. The Halogen Bond. Chem. Rev. 2016, 116 (4), 2478-2601. https://doi.org/10.1021/acs.chemrev.5b00484.

(5) Pavlicek, N.; Gross, L. Generation, Manipulation and Characterization of Molecules by Atomic Force Microscopy. Nat. Rev. Chem. 2017, 1, 0005. https://doi.org/10.1038/s41570-016-0005.

(6) Hla, S.-W.; Bartels, L.; Meyer, G.; Rieder, K.-H. Inducing All Steps of a Chemical Reaction with the Scanning Tunneling Microscope Tip: Towards Single Molecule Engineering. Phys. Rev. Lett. 2000, 85 (13), 2777-2780. https://doi.org/10.1103/PhysRevLett.85.2777.

(7) Crawford, A. G.; Liu, Z.; Mkhalid, I. A. I.; Thibault, M. H.; Schwarz, N.; Alcaraz, G.; Steffen, A.; Collings, J. C.; Batsanov, A. S.; Howard, J. A. K.; Marder, T. B. Synthesis of 2-and 2,7-Functionalized Pyrene Derivatives: An Application of Selective C-H Borylation. Chem. - A Eur. J. 2012, 18 (16), 5022-5035. https://doi.org/10.1002/chem.201103774.

(8) Wu, A.; Duan, Y.; Xu, D.; Penning, T. M.; Harvey, R. G. Regiospecific Oxidation of Polycyclic Aromatic Phenols to Quinones by Hypervalent Iodine Reagents. Tetrahedron 2010, 66 (12), 2111-2118. https://doi.org/10.1016/j.tet.2009.12.022. 